\title{
Liftoff and blowoff of a diffusion flame between parallel streams of fuel and air
}

\author{
Eduardo Fernández-Tarrazo ${ }^{a}$, Marcos Vera ${ }^{b, *}$, Amable Liñán ${ }^{c}$ \\ a I.N.T.A. Area de Propulsión-Edificio R02, Ctra. Ajalvir, km 4, 28850 Torrejón de Ardoz, Madrid, Spain \\ b Area de Mecánica de Fluidos, Universidad Carlos III de Madrid, 28911 Leganés, Spain \\ c Departamento de Motopropulsión y Termofluidodinámica, Universidad Politécnica de Madrid, Pza. Cardenal Cisneros 3 , \\ 28040 Mradrid Snrin
}

\section{Introduction}

Triple flame propagation along mixing layers plays an important role in the liftoff and blowoff of diffusion flames [1-10], as well as in the tran-

\footnotetext{
* Corresponding author. Fax: +34916249430.

E-mail address: marcos.vera@uc3m.es (M. Vera).
}

sient processes occurring after ignition [11-13], or after reignition following local extinction of the diffusion flames $[14,15]$. Such flames have been studied experimentally [16-24], theoretically [25-29], and numerically $[30,31]$, due to the role they play as transient laminar flamelets in partially premixed systems [32]. An extensive review of this work can be found elsewhere [33] and will not be repeated here for brevity. 
The first theoretical analysis of the two-dimensional structure of a triple flame is due to Dold and coworkers [25-27], who used a constant density model with a single-step chemical reaction with large activation energy. The analysis of triple flames was later extended to nonunity Lewis numbers by Daou and Liñán [28]. Using a different approach, Buckmaster [29] developed a simplified one-dimensional model containing some of the key physical ingredients of the problem. In all cases, the analysis predicted flames with advancing, retreating, or stationary edges depending on the Damköhler number.

The effects of thermal expansion on the propagation velocity of triple flames were first studied by Ruetsch et al. [30]. Due to thermal expansion effects in the curved flame-front region, the streamlines just upstream of the front are redirected outwards and the flow is slowed down before reaching the flame. As a result, the flame-front propagation velocity $U_{\mathrm{f}}^{\prime}$ relative to the upstream mixing layer is significantly larger than the stoichiometric planar flame velocity $S_{\mathrm{L}}$. The resulting ratio $U_{\mathrm{f}}^{\prime} / S_{\mathrm{L}}$ takes a value, which we find to be of the order of 3 , that we may expect to be dependent on the stoichiometric value of the mixture fraction, and also on the local upstream velocity and concentration gradients, both determined by the ratio $\delta_{\mathrm{L}} / \delta_{\mathrm{m}}$ of the characteristic laminar flame thickness, $\delta_{\mathrm{L}}$, to the effective thickness of the mixing layer, $\delta_{\mathrm{m}}$.

Thermal expansion effects are characterized by the dimensionless stoichiometric temperature increase $\gamma=\left(T_{\mathrm{s}}-T_{0}\right) / T_{0}$, where $T_{\mathrm{s}}$ denotes the stoichiometric flame temperature and $T_{0}$ is the temperature of the fresh gases. The flame-front propagation velocity $U_{\mathrm{f}}^{\prime}$ is known to increase, for large $\gamma$, as the square root of $\gamma$ [30]; but since the exothermicity parameter takes similar values for most hydrocarbons, e.g., $\gamma \simeq 6.7$ for methane beginning at ambient temperature, the front propagation velocity $U_{\mathrm{f}}^{\prime}$ is expected to remain relatively unchanged when different fuels are considered. Accordingly, in the present work the analysis will be carried out mainly for methane, although the results are expected to be similar for other fuels (as will be shown for propane).

In this paper we present a numerical description of the lifted diffusion flame in the mixing layer between two parallel streams of fuel and air, a configuration sketched in Fig. 1. Our main aim is directed to the calculations of freely propagating triple flames, away from the region in the near wake of the splitter plate that dominates the structure of the attachment region of the diffusion flames. Here, this region is described with the boundary conditions corresponding to the flow of the fuel and air resulting from injection through a porous wall, as done in some experimental configurations; see, for exam-

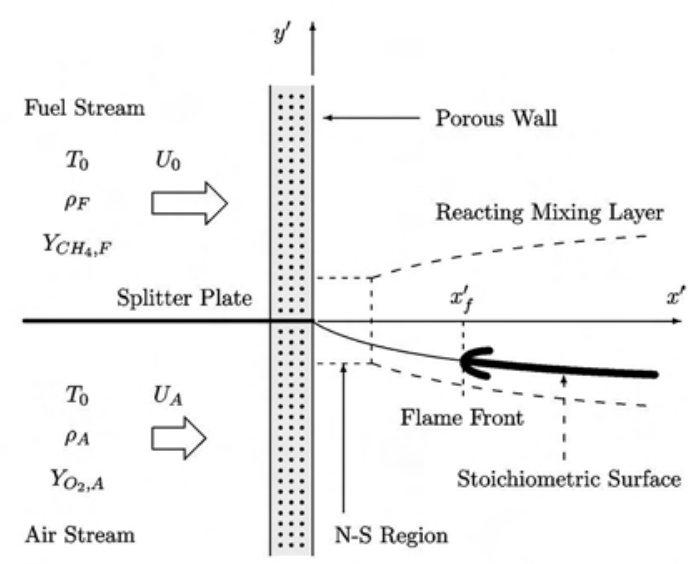

Fig. 1. Schematic illustration of the two-dimensional reacting mixing layer between parallel streams of fuel and air emerging from porous walls, showing the coordinates and the upstream boundary conditions.

ple, Walsh et al. [34]. Accordingly, we shall assume that the feeding streams come out normal from the porous wall with uniform velocities $U_{0}$ in the fuel stream and $U_{\mathrm{A}} \leqslant U_{0}$ in the air stream, and uniform temperature $T_{0}$. The wall, located at $x^{\prime}=0$, extends infinitely in the transverse direction, and the two streams are separated for $x^{\prime}<0$ by an infinitely thin splitter plate located at $y^{\prime}=0$. The analysis of the structure of the flow in other flow configurations at large Reynolds numbers, where the air and fuel boundary layers merge at the splitter plate, is more complex, involving for nonnegligible coflow of air a triple-deck structure. This analysis, of more relevance for the description of the attachment region of the diffusion flames in other flow configurations, has been the subject of previous work by the authors $[7,8]$.

For the configuration shown in Fig. 1 analyzed in this paper, the mixing layer originates from a NavierStokes region close to the splitter plate, where, even in the absence of chemical reaction, upstream diffusion and heat conduction are important. The scale $l_{\mathrm{N}}$ of the Navier-Stokes region is defined by $U_{0} l_{\mathrm{N}} / D_{\mathrm{TA}}=1$ in terms of the thermal diffusivity $D_{\mathrm{TA}}$ of the air stream at the initial temperature $T_{0}$. Further downstream, at distances $x^{\prime} \gg l_{\mathrm{N}}$, the Navier-Stokes region evolves to a slender mixing layer, with a thickness of order $\delta_{\mathrm{m}} \sim\left(D_{\mathrm{TA}} x^{\prime} / U_{0}\right)^{1 / 2} \ll x^{\prime}$. These quasi-planar mixing layers are encountered in slender laminar jetdiffusion flames at distances $x^{\prime}$ from the injector, small compared with the jet developing length, $L_{\mathrm{d}}=$ $a^{2} U_{0} / v_{\mathrm{A}}$, when the jet Reynolds number, of order $a U_{0} / D_{\mathrm{TA}}$, based on the initial radius $a$ of the fuel jet, is large compared with unity [35]. By an external localized energy source, we may ignite a flame in the mixing layer. The flame front, which only at early times may be a nearly spherical flame, will be rapidly 
elongated by the flow; the upstream part of the front soon reaches a quasi-stationary shape, and leaves behind a trailing diffusion flame; see, for example, the recent numerical simulations of Qin et al. [31]. In this case, for values of the fuel stream velocity $U_{0}$ smaller than a critical value, the flame may be anchored in the Navier-Stokes region near the injector wall, or lifted at distances $x_{\mathrm{f}}^{\prime} \ll L_{\mathrm{d}}$. Then, in the regime that we analyze, the front lies in the annular mixing layer that originates at the injector rim, which is locally planar in first approximation, with small relative errors of order $\delta_{\mathrm{m}} / a \ll 1$. The formulation of the problem of describing the structure of the flame-front region when the flame is lifted at distances of the order of $L_{\mathrm{d}}$ is given elsewhere [35].

We will try to describe the structure and dynamics of the upstream part of the flame front, which, when located at a distance $x_{\mathrm{f}}^{\prime} \ll L_{\mathrm{d}}$ from the porous wall, can propagate as a triple or edge flame with a front velocity $U_{\mathrm{f}}=d x_{\mathrm{f}}^{\prime} / d t$ relative to the injector, and can be stabilized at a distance $x_{l}^{\prime}$ determined by the condition $U_{\mathrm{f}}=0$. This liftoff distance depends strongly on $U_{0} / S_{\mathrm{L}}$, the ratio of the fuel stream velocity to the planar stoichiometric flame velocity, and on $U_{\mathrm{A}} / U_{0}$, the coflow velocity ratio, and more weakly on $\gamma$ and $S=s Y_{\mathrm{CH}_{4}, \mathrm{~F}} / Y_{\mathrm{O}_{2}, \mathrm{~A}}$, the air-to-fuel mass stoichiometric ratio, a thermochemistry parameter defined in terms of the mass fractions, $Y_{\mathrm{CH}_{4}, \mathrm{~F}}$ and $Y_{\mathrm{O}_{2}, \mathrm{~A}}$, of fuel and oxygen in the feeding streams, and the mass $s$ of oxygen required to burn, with the global reaction, the unit mass of fuel. Notice that $S$, with the assumption of unity Lewis numbers, leads to a value of the stoichiometric mixture fraction $Z_{\mathrm{s}}=1 /(S+1)$.

In the present paper we will not take into account the effects of the upstream velocity gradient. But unlike previous investigations, most of which have been devoted to the symmetric case $S=1$, we consider the realistically large values of $S$ encountered in diluted and undiluted hydrocarbon-air combustion, which leads to nonsymmetric flame fronts. In addition, the analysis takes fully into account the effects of thermal expansion and the changes in transport properties with temperature.

When the triple flame front is lifted at a distance $L_{\mathrm{d}} \gg x_{\mathrm{f}}^{\prime} \gg l_{\mathrm{N}}$, upstream of the front the mixing layer has a self-similar structure with a thickness $\delta_{\mathrm{m}}=$ $\left(D_{\mathrm{TA}} x_{\mathrm{f}}^{\prime} / U_{0}\right)^{1 / 2} \ll x_{\mathrm{f}}^{\prime}$. The structure of this mixing layer will be the same for the mixing layer that develops downstream of a fuel injector (without porous wall), when its thickness grows above the thickness of the boundary layer at the injector wall. Therefore, the results for lifted flames presented here are anticipated to be valid for more general configurations. In this regime, hereafter referred to as the lifted flame regime, the flame-front structure will depend not only on $S$ and $\gamma$, but on the local Damköhler number,
$D_{\mathrm{m}}=\left(\delta_{\mathrm{m}} / \delta_{\mathrm{L}}\right)^{2} \gg 1$, based on the thickness, $\delta_{\mathrm{m}}$, of the nonreacting mixing layer at the flame-front position and the laminar flame thickness, $\delta_{\mathrm{L}}=D_{\mathrm{TA}} / S_{\mathrm{L}}$. Note that the ratio $\delta_{\mathrm{L}} / \delta_{\mathrm{m}}$ measures in nondimensional form the upstream concentration gradients.

In the lifted flame regime, the flame-front structure is that of a curved premixed flame with a radius of curvature, of order $\delta_{\mathrm{m}}$, large compared with the flame-front thickness, of order $\delta_{\mathrm{L}}$. Correspondingly, the curved flame front propagates against the incoming flow as a quasi-planar premixed flame with a velocity $U_{\mathrm{L}}(\phi)$, depending mainly on the local mixture composition through the local value of the equivalence ratio, $\phi=s Y_{\mathrm{CH}_{4}, u} / Y_{\mathrm{O}_{2}, u}$, where $Y_{\mathrm{CH}_{4}, u}$ and $Y_{\mathrm{O}_{2}, u}$ are the mass fractions of fuel and oxygen just upstream of the flame-front. In the limit $D_{\mathrm{m}} \gg 1$, the flow is inviscid outside this thin premixed flame, and the equivalence ratio remains constant along the streamlines in the region of flow redirection ahead of the front. Thus, one could in principle solve the flow in the flame-front region by considering the flame as an infinitely thin curved reaction sheet propagating at a normal velocity $U_{\mathrm{L}}(\phi)$ with respect to the incoming flow and embedded in the inviscid flow region, but the numerical solution of the resulting free boundary problem is anticipated to be difficult, since the front will be subject to the Darrieus-Landau instability. For this reason, we shall use here the alternative approach of integrating the complete set of conservation equations for large but finite values of $D_{\mathrm{m}}$.

From the above discussion, it is clear that the dependence of the planar-flame velocity with $\phi$ enters as the essential ingredient of the influence of the kinetics on the curved flame-front structure in the lifted flame regime. Therefore, a realistic model for the fuel consumption rate, able to capture this dependence, must be employed for an accurate computation of flamefront velocities. We will assume a one-step overall Arrhenius reaction, allowing the activation energy $E$ to vary with the local value of the equivalence ratio in order to reproduce the experimentally observed variation of the planar flame velocity. However, we emphasize that the formulation presented here remains valid for more general chemical kinetic schemes; nevertheless, the results are anticipated to be similar in the limit $D_{\mathrm{m}} \gg 1$.

For steady lifted flames, the results, given here for both diluted and undiluted fuel streams in the case $U_{\mathrm{A}}=U_{0}$, relate the ratio, $U_{\mathrm{f}}^{\prime} / S_{\mathrm{L}}=\left(U_{0}-U_{\mathrm{f}}\right) / S_{\mathrm{L}}$, of the front velocity (relative to the upstream flow) to the planar stoichiometric flame velocity with the Damköhler number, $D_{\mathrm{m}}$, and also give the liftoff distance $x_{l}^{\prime}$ as a function of the Damköhler number. For large values of $D_{\mathrm{m}}$, the results provide values of the front propagation velocity that are in good agreement with previous experimental results, yield- 
ing well-defined conditions for blowoff. As will be discussed below, for unsteady lifted flames, the dynamics of the flame front is still given by the universal description of the lifted flame regime.

In order to describe the transition from the attached regime to the freely propagating (or lifted) regime we have analyzed, with the same overall $\mathrm{ki}$ netic law, the case where the flame front is located close to the porous wall, at a distance $x_{f}^{\prime}$ of the order of the Navier-Stokes length, $l_{\mathrm{N}}$. In this regime, hereafter referred to as the attached flame regime, the flamefront structure becomes that of an edge flame, where upstream heat conduction to the injection wall plays an essential role. This regime corresponds to values of order unity or larger of the ratio $D_{\mathrm{N}}=\left(S_{\mathrm{L}} / U_{0}\right)^{2}$ of the residence time in the Navier-Stokes region $D_{\mathrm{TA}} / U_{0}^{2}$ to the reaction time $D_{\mathrm{TA}} / S_{\mathrm{L}}^{2}$, which is the relevant Damköhler number for the analysis of attached flames.

An important kinetic parameter is the ratio $U_{0} / S_{\mathrm{L}}$ $=D_{\mathrm{N}}^{-1 / 2}$ of the fuel stream velocity to the planar flame velocity, $S_{\mathrm{L}}$, of the stoichiometric mixture formed with the unit mass of the fuel stream and a mass $S$ of the air stream. We anticipate that the flame will be blown off if $U_{0} / S_{\mathrm{L}}$ rises above a blowoff value $\left(U_{0} / S_{\mathrm{L}}\right)_{\mathrm{b}}$, of order unity, to be calculated; due to thermal expansion effects this value is moderately large compared with unity. Although the results presented here will be restricted to the case $U_{\mathrm{A}} / U_{0}=1$, we can anticipate that the blowoff value of $U_{0} / S_{\mathrm{L}}$ will be of order $S$ for small values of $U_{\mathrm{A}} / U_{0}$.

The analysis begins in Section 2 with the description of the steady flame front in the attached flame regime. The (quasi-steady) numerical description of the flame-front region in the lifted flame regime is given in Section 3. The numerical results are discussed in Section 4. Finally, the concluding remarks are presented in Section 5.

\section{The attached flame regime}

In this section we describe the steady flame-front structure when the front is located close to the porous wall, at a distance $x_{f}^{\prime}$ of the order of the Navier-Stokes length, $l_{\mathrm{N}}$. The conservation equations are written in nondimensional form using the Navier-Stokes length $l_{\mathrm{N}}=D_{\mathrm{TA}} / U_{0}$ as characteristic length scale to define the dimensionless streamwise and transverse coordinates, $x=x^{\prime} / l_{\mathrm{N}}$ and $y=y^{\prime} / l_{\mathrm{N}}$, and using the injection velocity of the fuel stream $U_{0}$ as scale to define the corresponding dimensionless velocity components, $u=u^{\prime} / U_{0}$ and $v=v^{\prime} / U_{0}$, respectively. In addition, the density $\rho^{\prime}$ is measured with the density $\rho_{\mathrm{A}}$ of the air stream, the temperature $T^{\prime}$ is measured with the initial temperature $T_{0}$ of the feeding streams, and the pressure differences from the hydrostatic far-field value are scaled with the dynamic pressure $\rho_{A} U_{0}^{2}$. Hereafter, dimensional variables will be denoted by a prime.

\subsection{Conservation equations}

The nondimensional conservation equations of mass, momentum, species, and energy can be written as follows:

$$
\begin{aligned}
& \begin{aligned}
\nabla \cdot(\rho \mathbf{v})=0, & \\
\nabla \cdot(\rho \mathbf{v v})= & -\nabla p+\operatorname{Pr} \nabla \cdot \tau, \\
\nabla \cdot\left(\rho \mathbf{v} Y_{\alpha}\right)= & L e_{\alpha}^{-1} \nabla \cdot\left(\rho D_{T} \nabla Y_{\alpha}\right) \\
& +D_{\mathrm{N}} \omega_{\alpha} \quad\left(\alpha \neq \mathrm{N}_{2}\right), \\
\nabla \cdot(\rho \mathbf{v} h)=\nabla \cdot & {\left[k \nabla T+\sum_{\alpha \neq \mathrm{N}_{2}}\left(h_{\alpha}-h_{\mathrm{N}_{2}}\right)\right.} \\
& \left.\quad \times L e_{\alpha}^{-1} \rho D_{T} \nabla Y_{\alpha}\right],
\end{aligned}
\end{aligned}
$$

where $\mathbf{v}=(u, v)$ is the velocity vector, $\tau$ is the dimensionless viscous stress tensor, and the subscript $\alpha$ denotes chemical species. The unsteady terms have been dropped since we are only interested in steady solutions; these terms should be retained if, for instance, we were interested in the development of edge flame oscillations, as occurs when the volumetric heat loss is sufficiently strong [36]. The above equations must be supplemented with the equation of state

$\rho T=M / M_{\mathrm{A}}$,

where $M_{\mathrm{A}}$ is the mean molecular mass in the air stream and $M=\left(\sum_{\alpha} Y_{\alpha} / M_{\alpha}\right)^{-1}$ is the mean molecular mass of the mixture, and the relation derived from mass conservation

$Y_{\mathrm{N}_{2}}=1-\sum_{\alpha \neq \mathrm{N}_{2}} Y_{\alpha}$,

which provides the mass fraction of the inert species. Since the typical Mach number is in most applications small compared with unity, we have neglected the pressure variations in the equation of state and the kinetic energy and viscous dissipation in the energy equation. The nondimensional reaction term $\left(l_{\mathrm{N}} / U_{0}\right) \omega_{\alpha}^{\prime} / \rho_{\mathrm{A}}$ has been written in the form $D_{\mathrm{N}} \omega_{\alpha}$ in terms of the relevant Damköhler number in the attached flame regime, $D_{\mathrm{N}}=\left(S_{\mathrm{L}} / U_{0}\right)^{2}$, by measuring the overall reaction rate $\omega_{\alpha}^{\prime} / \rho_{\mathrm{A}}$ with its characteristic value $1 / t_{\mathrm{L}}=S_{\mathrm{L}} / \delta_{\mathrm{L}}=S_{\mathrm{L}}^{2} / D_{\mathrm{TA}}$, to obtain a nondimensional reaction rate $\omega_{\mathrm{F}}$, of order unity in the premixed flame layers, which is a function of the temperature and the reactants mass fractions. This is given below in Eq. (13) for an overall Arrhenius reaction. 


\subsection{Boundary conditions}

Equations (1)-(5) must be solved, for $\alpha \neq \mathrm{N}_{2}$, with the following boundary conditions:

$$
\begin{aligned}
& x=0, \quad y>0: \\
& u-1=v=T-1=0, \\
& \quad \rho\left[\left.Y_{\alpha}\right|_{0^{+}}-Y_{\alpha, \mathrm{F}}\right]-L e_{\alpha}^{-1} \rho D_{T}\left(\partial Y_{\alpha} / \partial x\right)=0, \quad(7) \\
& x=0, \quad y<0 ; \\
& u-U_{\mathrm{A}} / U_{0}=v=T-1=0, \\
& \quad \rho\left(U_{\mathrm{A}} / U_{0}\right)\left[\left.Y_{\alpha}\right|_{0^{+}}-Y_{\alpha, \mathrm{A}}\right] \\
& \quad-L e_{\alpha}^{-1} \rho D_{T}\left(\partial Y_{\alpha} / \partial x\right)=0, \\
& x>0, \quad y \rightarrow+\infty: \\
& u \rightarrow 1, \quad v \rightarrow 0, \quad T \rightarrow 1, \quad Y_{\alpha} \rightarrow Y_{\alpha, \mathrm{F}}, \\
& x>0, \quad y \rightarrow-\infty: \\
& u \rightarrow U_{\mathrm{A}} / U_{0}, \quad v \rightarrow 0, \quad T \rightarrow 1, \quad Y_{\alpha} \rightarrow Y_{\alpha, \mathrm{A}} .
\end{aligned}
$$

Far downstream of the injection wall, as $x \rightarrow \infty$, the solution will evolve to a flow that involves slow variations with $x$, associated with transversal diffusion effects, which could be described using approximations of the boundary-layer type. But instead of using this asymptotic solution as downstream boundary condition, when solving the system of Eqs. (1)-(4), a weak form of the boundary conditions, such as

$\frac{\partial u}{\partial x}=\frac{\partial Y_{\alpha}}{\partial x}=\frac{\partial T}{\partial x}=0 \quad$ as $x \rightarrow \infty$,

will be employed for simplicity.

In the above equations we use Fick's law to evaluate the (molecular) mass flux of species $\alpha$, the heat flux vector is written in terms of the generalized Fourier law, and the transport coefficients are nondimensionalized with their corresponding values in the air stream. In particular, the multicomponent transport properties for methane-air mixtures will be evaluated using the model proposed by Smooke and Giovangigli [37], where the Prandt number, $P r=\mu^{\prime} c_{\mathrm{p}}^{\prime} / k^{\prime}$, and the Lewis numbers. $L e_{\alpha}=k^{\prime} /\left(\rho^{\prime} c_{\mathrm{p}}^{\prime} D_{\alpha}^{\prime}\right)$, are assumed to be constant: $P r=0.75, L e_{\mathrm{O}_{2}}=1.11, L e_{\mathrm{CH}_{4}}=0.97, L e_{\mathrm{H}_{2} \mathrm{O}}=$ $0.83, \mathrm{LeCO}_{2}=1.39$, and the dependence of the thermal conductivity on the temperature is approximated by a power law of the form $\mu=\rho D_{T}=k / c_{\mathrm{p}}=T^{\sigma}$ with $\sigma=0.7$.

In addition, botb the specific heat at constant pressure and the enthalpy of the mixture, $c_{\mathrm{p}}=\sum_{\alpha} Y_{\alpha} c_{\mathrm{p} \alpha}$ and $h=\sum_{\alpha} Y_{\alpha} h_{\alpha}$, nondimensionalized here using $c_{\mathrm{p} A}$ (the specific heat at constant pressure in the air stream) and $c_{\mathrm{p} A} T_{0}$, respectively, are calculated in terms of the dimensionless specific heats, $c_{\mathrm{p} \alpha}$, and enthalpies, $h_{\alpha \alpha}$, of species $\alpha$; these, in turn, are evaluated using the NASA polynomial formulae, with the coefficients $a_{i}$ taken from the GRI-Mech database [38].

\subsection{Chemistry model}

To complete the problem formulation, one needs to provide an expression for the fuel consumption rate. Here, we shall consider an overall irreversible reaction where the fuel reacts with the oxygen to produce combustion products and heat according to

$\mathrm{CH}_{4}+2 \mathrm{O}_{2} \rightarrow 2 \mathrm{H}_{2} \mathrm{O}+\mathrm{CO}_{2}+(Q)$.

where $q=Q / M_{\mathrm{CH}_{4}}$ represents the amount of heat released per unit mass of fuel consumed, written here in terms of the molar heat of reaction, $Q$, and the molecular mass of methane. $M_{\mathrm{CH}_{4}}$. In this simple case, Eq. (3) must be solved for $\alpha=\mathrm{O}_{2}, \mathrm{CH}_{4}, \mathrm{H}_{2} \mathrm{O}$, and $\mathrm{CO}_{2}$, while the mass fraction of the inert species, $\mathrm{N}_{2}$, can be obtained from overall mass conservation using Eq. (6).

It is further assumed that the local rate at which reaction (12) takes place depends on the mass fractions of fuel (methane) and oxygen, $Y_{\mathrm{CH}_{4}}$ and $Y_{\mathrm{O}_{2}}$, and on the absolute temperature $T^{\prime}$ through an Arrhenius law of the form

$$
\begin{aligned}
\omega_{\mathrm{CH}_{4}} & =\frac{16}{64} \omega_{\mathrm{O}_{2}}=-\frac{16}{36} \omega_{\mathrm{H}_{2} \mathrm{O}}=-\frac{16}{44} \omega_{\mathrm{CO}_{2}} \\
& =-\frac{S_{\mathrm{L}}^{2} \rho^{2} B}{D_{\mathrm{TA}} \rho_{\mathrm{A}}} Y_{\mathrm{CH}_{4}} Y_{\mathrm{O}_{2}} \exp \left(-E / R T^{\prime}\right)
\end{aligned}
$$

involving a frequency factor $B$, an activation energy $E$, and the universal gas constant $R=8.314 \mathrm{~J} /$ (mol K). As discussed above, we have measured here the dimensional reaction rates $\omega_{\alpha}^{\prime}$ with the scale $s_{\mathrm{L}}^{2} /\left(D_{\mathrm{TA}} \rho_{\mathrm{A}}\right)$ to obtain the above dimensionless expressions.

Modifications to Eq. (13) are in general needed for an accurate description of this dependence, including for instance reaction orders different from unity for both fuel and oxidizer (Westbrook and Dryer [39]). However, we have chosen in the calculations presented below the approach, recently adopted by Garrido-López and Sarkar [40], of considering a variable activation energy selected as a function of the local equivalence ratio

$\phi=s Y_{\mathrm{CH}_{4}, u} / Y_{\mathrm{O}_{2}, u}$

to mimic the dependence on $\phi$ of the planar flame velocity. Here, the local equivalence ratio is defined in terms of the mass fractions of methane and oxygen in the upstream fresh mixture, given, in first approximation, by

$$
Y_{\mathrm{CH}_{4}, u}=Z Y_{\mathrm{CH}_{4}, F} \text { and } Y_{\mathrm{O}_{2, t}}=(1-Z) Y_{\mathrm{O}_{2}, A} \text {. }
$$



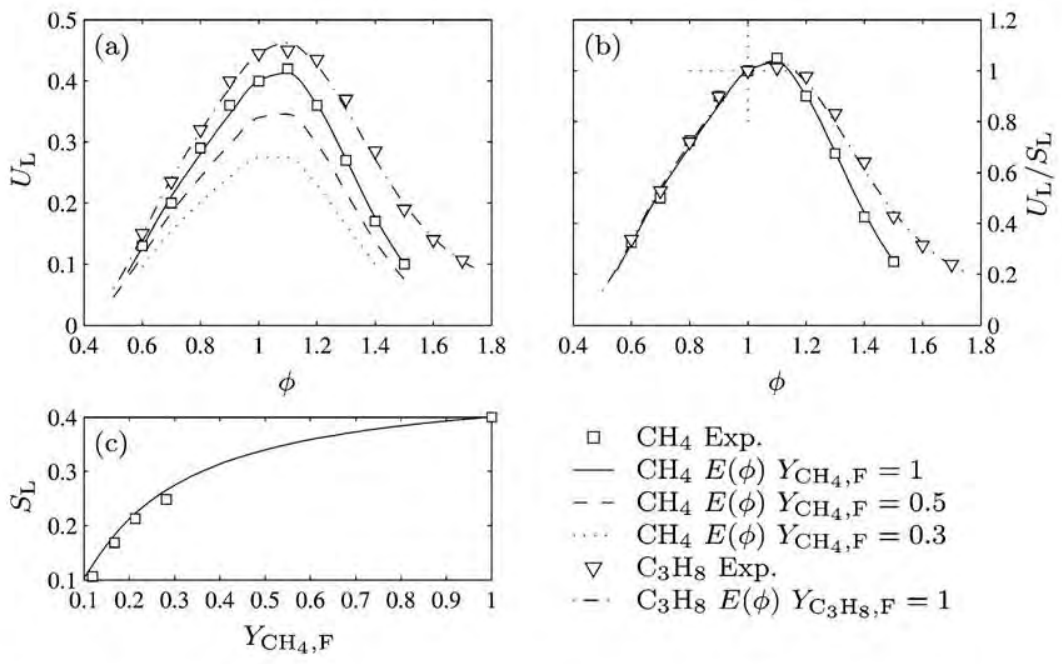

Fig. 2. (a) Propagation velocity of planar methane- and propane-air flames for different values of the equivalence ratio and different dilutions of the fuel stream employed to generate the mixture (see legend for details). (b) Propagation velocity of planar undiluted methane- and propane-air flames normalized with the corresponding stoichiometric flame velocity, $S_{\mathrm{L}, \mathrm{CH}_{4}}=0.4 \mathrm{~m} / \mathrm{s}$ and $S_{\mathrm{L}, C_{3} H_{8}}=0.445 \mathrm{~m} / \mathrm{s}$. (c) Propagation velocity of a planar stoichiometric methane-air flame as a function of the dilution, $Y_{\mathrm{CH}_{4}, \mathrm{~F}}$, of the fuel stream employed to generate the mixture.

where

$$
Z=\left(S Y_{\mathrm{CH}_{4}} / Y_{\mathrm{CH}_{4}, F}-Y_{\mathrm{O}_{2}} / Y_{\mathrm{O}_{2}, A}+1\right) /(1+S)
$$

is a mixture-fraction-like variable, of unit concentration in the fuel stream and zero concentration in the air stream, which can be calculated in terms of the local values of the reactants mass fractions $Y_{\mathrm{CH}_{4}}$ and $Y_{\mathrm{O}_{2}}$. Strictly speaking, the above expressions relating $Y_{\mathrm{CH}_{4}, u}$ and $Y_{\mathrm{O}_{2}, u}$ with $Z$ are based on an implicit assumption of equal Lewis numbers for fuel and oxidizer, since then $Z$ is a conserved scalar whose value does not vary across the flame. Note that the Lewis numbers of fuel and oxidizer in methane-air mixtures are very close to each other, so that this is a good approximation.

In particular, we shall use here the following expression for the dependence of the overall activation energy on the equivalence ratio:

$$
\frac{E(\phi)}{E_{0}}= \begin{cases}1+2(0.7-\phi)^{2} & \text { for } \phi \leqslant 0.7, \\ 1 & \text { for } 0.7 \leqslant \phi \leqslant 1.0, \\ 1+1.472(\phi-1)^{2} & \text { for } 1.0 \leqslant \phi,\end{cases}
$$

where $E_{0}=1.25 \times 10^{5} \mathrm{~J} /(\mathrm{mol} \mathrm{K})$ is an appropriate (sufficiently high) activation energy of the overall reaction for a stoichiometric mixture. For this value of $E_{0}$ we selected the frequency factor $B$ appearing in the Arrhenius law (13) so as to reproduce the experimental value of $S_{\mathrm{L}}$ for undiluted methane-air mixtures, yielding $B=4 \times 10^{14} \mathrm{~cm}^{3} /(\mathrm{mols})$.

Fig. 2 shows numerical calculations of laminar flame velocities for undiluted methane- and propane- air mixtures, as well as diluted methane-air mixtures, as a function of the equivalence ratio $\phi$, along with the experimental values given by Egolfopoulos et al. [41] (see also Law [42]). For methane-air mixtures, the figure also shows the value obtained with the above law $E(\phi)$ of the planar flame velocity $S_{\mathrm{L}}$ of the stoichiometric mixture formed with the unit mass of the fuel stream (methane diluted with nitrogen, with methane mass fraction $Y_{\mathrm{CH}_{4}, \mathrm{~F}}$ ) and a mass $S$ of the air stream, together with the experimental values reported by Egolfopoulos and Law [43]. As can be seen, using an overall Arrhenius reaction together with the law (17) we are able to reproduce with small errors the experimental dependence of the planar-flame propagation velocity with the equivalence ratio within flammability limits, as well as the variation of $S_{\mathrm{L}}$ with the dilution of the fuel stream. Another advantage of this approach, also noted by Garrido-López and Sarkar [40], is that it does not add stiffness to the chemical term, as is known to occur with other simplified schemes [39].

We should note that the influence of the kinetics on the flame-front structure is far more complex than suggested by the above discussion, specially in the attached flame regime. In this regime, the diffusion flame is close to extinction conditions and the structure of the flame front differs substantially from that of a premixed flame. Accordingly, in addition to accurately predicting the dependence of $S_{\mathrm{L}}$ with $\phi$ and $Y_{\mathrm{CH}_{4}, \mathrm{~F}}$, we have also tested the ability of the chemistry model to predict diffusion-flame extinction. This shows a degree of uncertainty slightly larger than that 
of the detailed chemistry calculations found in the literature (even though the adjustable parameters of our model were not chosen so as to mimic also extinction conditions). In particular, in the potential flow configuration our model predicts a critical strain rate at extinction of $756 \mathrm{~s}^{-1}$, between 40 and $50 \%$ above the 509-544 $\mathrm{s}^{-1}$ range suggested by Chelliah et al. [44]. Similar uncertainties can be found in detailed calculations $[45,46]$, which yield extinction values as high as $40 \%$ larger than the experimentally observed values [44,47-49]. In the plug flow configuration the available experimental data give critical strain rates at extinction of the order of $380 \mathrm{~s}^{-1}[44,49]$, while recent detailed chemistry calculations [50] provide numerical values between 470 and $560 \mathrm{~s}^{-1}$, depending also on the molecular transport model employed in the computations.

With respect to the performance of the model at ignition, it should be emphasized that at low (i.e., ambient) temperatures the ignition delay time is too large compared to the characteristic residence time for spontaneous ignition to take place, and therefore spontaneous flame ignition is not expected to play an important role in the structure and dynamics of attached/lifted flames. As a result, the performance of the chemistry model at ignition is not critical here. By contrast, the triple flame encountered in unsteady or parallel mixing layers, described by Liñán and Crespo [51], when initiated at high enough initial temperatures by the heat release due to the reaction (as typically occurs in supersonic combustion) is not associated with the upstream heat conduction of ordinary edge flames.

In short, despite the complex underlying physicalchemical aspects of the problem, our aim here is to provide a general understanding of the quasi-steady structure of attached and lifted laminar flame fronts, and to identify orders of magnitude and controlling parameters. Thus, a simple one-step chemistry model is preferred for illustrative purposes. Although this simple chemistry model is not expected to quantitatively describe the detailed internal flame structure in the attached flame regime, the results presented below are of great interest for the calculation of liftoff heights in lifted nonpremixed flames, as well as for examining the flow field in the flame-front region and assessing the transition of a triple flame into an edge flame as the flame front approaches the injection wall.

\section{The lifted flame regime}

Our aim in this section is to describe the structure and dynamics of the upstream part of the flame front, of size of order $\delta_{\mathrm{m}}$, that when located at a station $L_{\mathrm{d}} \gg x_{\mathrm{f}}^{\prime}(t) \gg l_{\mathrm{N}}$ will propagate downstream with a velocity $U_{\mathrm{f}}=\mathrm{d} x_{\mathrm{f}}^{\prime} / \mathrm{d} t$ relative to the injector. We can expect $U_{\mathrm{f}}$ to be of order $S_{\mathrm{L}}$ when the flow velocity is also of order $S_{\mathrm{L}}$. If the flame lies at the liftoff distance $x_{\mathrm{f}}^{\prime}=x_{l}^{\prime}$, then $U_{\mathrm{f}}=0$. If at a given station $U_{\mathrm{f}}$ turns out to be negative, the front will propagate upstream relative to the injector; if positive, the front will propagate downstream.

As will become clear in Section 4 below, for sufficiently small values of the Damköhler number $D_{\mathrm{N}}=$ $\left(S_{\mathrm{L}} / U_{0}\right)^{2}$ the diffusion flame edge is located at a distance $x_{\mathrm{f}}^{\prime} \gg l_{\mathrm{N}}$ downstream from the porous wall. Clearly, as $x_{\mathrm{f}}^{\prime} / l_{\mathrm{N}}$ grows the numerical description of the flame-front region becomes increasingly difficult, since the computational domain, which in the attached flame regime includes the injection wall as upstream boundary, must be extended further and further downstream if we want to resolve the flame-front region. This suggests that an alternative formulation is needed for the description of the flow when the flame front is located far away from the injector.

In the so-called lifted flame regime, upstream of the flame front a mixing layer develops where the chemical reaction can be considered frozen. At distances $x^{\prime} \gg l_{\mathrm{N}}$ from the porous wall this mixing layer is slender, and it can be described using the boundary-layer approximation. Indeed, a selfsimilar description is available for the frozen mixing layer, with the velocity $u(\eta)$ and mixture composition $Y_{\alpha}(\eta)$ given in terms of the similarity variable $\eta=y^{\prime} /\left(D_{\mathrm{TA}} x^{\prime} / U_{0}\right)^{1 / 2}$. Introducing the similarity stream function $F(\eta)$, defined from $\psi=$ $\rho_{\mathrm{A}} U_{0}\left(D_{\mathrm{TA}} x^{\prime} / U_{0}\right)^{1 / 2} F$, reduces the problem (1)-(3) to that of integrating

$$
\begin{aligned}
& \frac{d F}{d \eta}=\rho u, \\
& -\frac{1}{2} F \frac{d u}{d \eta}=\operatorname{Pr} \frac{d^{2} u}{d \eta^{2}}, \\
& -\frac{1}{2} F \frac{d Y_{\alpha}}{d \eta}=L e_{\alpha}^{-1} \frac{d^{2} Y_{\alpha}}{d \eta^{2}} \quad\left(\alpha=\mathrm{O}_{2}, \mathrm{CH}_{4}\right)
\end{aligned}
$$

together with the equation of state (5) and with $Y_{\mathrm{N}_{2}}=$ $1-Y_{\mathrm{O}_{2}}-Y_{\mathrm{CH}_{4}}$. The boundary conditions are

$$
\begin{aligned}
\eta \rightarrow+\infty & : \\
u-1 & =F-\left(\rho_{\mathrm{F}} / \rho_{\mathrm{A}}\right)\left(\eta-\eta_{\mathrm{F}}\right) \\
& =Y_{\mathrm{CH}_{4}}-Y_{\mathrm{CH}_{4}, \mathrm{~F}}=Y_{\mathrm{O}_{2}}=0,
\end{aligned}
$$

$\eta \rightarrow-\infty$ :

$$
\begin{aligned}
u-\left(U_{\mathrm{A}} / U_{0}\right) & =F-\left(U_{\mathrm{A}} / U_{0}\right)\left(\eta-\eta_{\mathrm{A}}\right) \\
& =Y_{\mathrm{CH}_{4}}=Y_{\mathrm{O}_{2}}-Y_{\mathrm{O}_{2}, \mathrm{~A}}=0,
\end{aligned}
$$

where the constants $\eta_{\mathrm{F}}$ and $\eta_{\mathrm{A}}$ are to be calculated as part of the solution. Note that in the chemically frozen mixing layer upstream from the flame front $Y_{\mathrm{CO}_{2}}=$ $Y_{\mathrm{H}_{2} \mathrm{O}}=T-T_{0} \equiv 0$. 
It should be noted that Eqs. (19)-(22) remain invariant under translations in $\eta$. Accordingly, the transverse velocity $v=-\rho^{-1}\left[\left(U_{0} x^{\prime} / D_{\mathrm{TA}}\right)^{-1 / 2} / 2\right](F-$ $\eta d F / d \eta)$ will not be uniquely determined unless we specify an additional condition to fix the origin of $\eta$. This condition emerges from the fact that, for large Reynolds numbers, the pressure must be continuous across the mixing layer in first approximation. The perturbation flow induced in the air and fuel streams by the transverse displacement velocities generated by the mixing process is irrotational. This flow gives a nonzero slip velocity at both sides of the mixing layer, thereby inducing a pressure perturbation which can be easily calculated using the Bernoulli equation. Linearizing the Bernoulli equation, the condition of equality of pressures at both sides of the interface can be written as $\rho_{\mathrm{A}} \eta_{\mathrm{A}}=-\rho_{\mathrm{F}} \eta_{\mathrm{F}}$, which is the desired condition that fixes the origin of $\eta$. We have found numerically that, in the particular case $U_{\mathrm{A}} / U_{0}=1$, the constants $\eta_{\mathrm{F}}$ and $\eta_{\mathrm{A}}$ can be set equal to zero with an appropriate choice of the origin of $\eta$, implying that the displacement velocities are also zero. However, this will not be the case in a more general situation where $U_{\mathrm{A}} / U_{0}<1$.

At the flame location, $x^{\prime}=x_{\mathrm{f}}^{\prime}$, the chemically frozen mixing layer has a thickness $\delta_{\mathrm{m}}=\left(D_{\mathrm{TA}} x_{\mathbf{f}}^{\prime}\right)$ $\left.U_{0}\right)^{1 / 2}$, so that the velocity and mixture composition are given by

$$
\tilde{Y}_{\alpha}=Y_{\alpha}\left(y^{\prime} / \delta_{\mathrm{m}}\right), \quad \tilde{u}=u\left(y^{\prime} / \delta_{\mathrm{m}}\right) .
$$

These distributions are to be used as boundary conditions when integrating Eqs. (24)-(27) for the flamefront region, written below in terms of the coordinates $y^{\prime} / \delta_{\mathrm{m}}$ and $\left(x^{\prime}-x_{\mathbf{f}}^{\prime}\right) / \delta_{\mathrm{m}}$

In order to describe the flow in the flame-front region we shall use a reference frame moving with the front. Because the fluid transient time, $\delta_{\mathrm{m}} / U_{0}$, across this region is small compared with the time $x_{\mathrm{f}}^{\prime} / U_{0}$ required to see changes in the upstream conditions encountered by the front, we can consider the flow structure as quasi-steady relative to this reference system.

The conservation equations, written in nondimensional form using $\delta_{\mathrm{m}}$ as scale for the streamwise and transverse coordinates, $\chi=\left(x^{\prime}-x_{\mathrm{f}}^{\prime}\right) / \delta_{\mathrm{m}}$ and $\zeta=y^{\prime} / \delta_{\mathrm{m}}, S_{\mathrm{L}}$ for the two velocity components, $U=$ $u^{\prime} / S_{\mathrm{L}}$ and $V=v^{\prime} / S_{\mathrm{L}}$, and $\rho_{\mathrm{A}} S_{\mathrm{L}}^{2}$ for the pressure differences from the hydrostatic far-field value, take the form

$$
\begin{aligned}
& \nabla \cdot(\rho \mathbf{V})=0, \\
& \begin{aligned}
\nabla \cdot(\rho \mathbf{V} \mathbf{V})= & -\nabla p+D_{\mathrm{m}}^{-1 / 2} \operatorname{Pr} \nabla \cdot \tau, \\
\nabla \cdot\left(\rho \mathbf{V} Y_{\alpha}\right)= & D_{\mathrm{m}}^{-1 / 2} L e_{\alpha}^{-1} \nabla \cdot\left(\rho D_{T} \nabla Y_{\alpha}\right) \\
& \quad+D_{\mathrm{m}}^{1 / 2} \omega_{\alpha} \quad\left(\alpha \neq \mathrm{N}_{2}\right),
\end{aligned}
\end{aligned}
$$

$$
\begin{aligned}
\nabla \cdot(\rho \mathbf{V} h)=D_{\mathrm{m}}^{-1 / 2} \nabla \cdot\left[k \nabla T+\sum_{\alpha \neq \mathrm{N}_{2}}\left(h_{\alpha}-h_{\mathrm{N}_{2}}\right)\right. \\
\left.\times L e_{\alpha}^{-1} \rho D_{T} \nabla Y_{\alpha}\right]
\end{aligned}
$$

supplemented by the equation of state (5) and Eq. (6). Here we consider the same transport properties and thermochemical model used in the attached flame regime, and both the gradient operator $\nabla(\cdot)$ and the nondimensional viscous stress tensor $\tau$ now involve derivatives with respect to $\chi$ and $\zeta$. Upstream from the flame-front region, the flow is given by the selfsimilar description of the frozen mixing layer, which provides us with the upstream boundary conditions

$$
\begin{aligned}
\chi \rightarrow-\infty: \quad Y_{\alpha}=\widetilde{Y}_{\alpha}(\zeta), T=T_{0}, \\
\\
U=-U_{\mathrm{f}} / S_{\mathrm{L}}+\left(U_{0} / S_{\mathrm{L}}\right) \tilde{u}(\zeta) .
\end{aligned}
$$

In these conditions, derived from Eq. (23), the ratio $U_{0} / S_{\mathrm{L}}$ appears together with the front propagation velocity $U_{\mathrm{f}} / S_{\mathrm{L}}$, which is to be calculated. If we want to account for the perturbation in the upstream-flow velocities that results from the effect of the thermal expansion in the flame-front region, we should modify the upstream velocity profile $\tilde{u}(\zeta)$ appearing in Eq. (28) to include the flow perturbation associated with a linear volumetric source of strength $b \delta_{\mathrm{m}} S_{\mathrm{L}}$, placed at $x^{\prime}=x_{\mathrm{f}}^{\prime}$ and $y=0$, with $b$, of order unity, to be calculated as part of the solution. However, these velocity perturbations decay like $\chi^{-1}$, and their effects in the upstream velocity profile can be minimized by extending the computational domain sufficiently far upstream from the flame-front region, as done in the present work (instead of modifying the upstream velocity profile). Similarly, the effect of the thermal expansion in the trailing diffusion flame generates a flow perturbation, corresponding to a distribution of linear volumetric sources, that decays as $\chi^{-1 / 2}$. In the numerical calculations, the perturbations induced by the sources located inside the computational domain are automatically accounted, while the effects of the sources laying downstream of the computational domain will be neglected. Note that the displacement velocities induced by the trailing diffusion flame, of order $D_{\mathrm{TA}} / \delta_{\mathrm{m}}$, become negligible compared to the displacement velocities introduced by the curved premixed flames, of order $S_{\mathrm{L}}$, as the Damköhler $D_{\mathrm{m}}=\left(\delta_{\mathrm{m}} / \delta_{\mathrm{L}}\right)^{2}$ grows to large values. As a final remark, it should be kept in mind that when the velocities of the two feeding streams are equal the displacement velocities in the upstream frozen mixing layer are identically zero, and therefore we can consistently set the upstream-flow transversal velocities equal to zero.

As previously discussed, downstream, as $\chi \rightarrow \infty$, the solution will evolve to a flow that involves slow 
variations with $\chi$, associated with transverse diffusion effects, which can be described using approximations of the boundary-layer type. But instead of using the asymptotic solution as the downstream boundary condition, when solving the system of Eqs. (24)-(27), a weak form of the boundary conditions, such as

$\frac{\partial U}{\partial \chi}=\frac{Y_{\alpha}}{\partial \chi}=\frac{\partial T}{\partial \chi}=0 \quad$ as $\chi \rightarrow \infty$,

can be employed for simplicity. In addition, we use the following lateral boundary conditions:

$$
\begin{aligned}
\zeta \rightarrow+\infty: & \\
Y_{\alpha}-Y_{\alpha, \mathrm{F}} & =T-T_{0}=U-\left(U_{0} / S_{\mathrm{L}}\right)=0, \\
\zeta \rightarrow-\infty: & \\
Y_{\alpha}-Y_{\alpha, \mathrm{A}} & =T-T_{0} \\
& =U-\left(U_{\mathrm{A}} / U_{0}\right)\left(U_{0} / S_{\mathrm{L}}\right)=0 .
\end{aligned}
$$

To complete the boundary conditions, we must add a condition linking the origin of the coordinate system to the flame-front. Note that in the formulation for the lifted flame regime the flame-front distance $x_{\mathrm{f}}^{\prime}$ and the Damköhler number $D_{\mathrm{N}}$ appearing in the attached flame regime are replaced by the more relevant Damköhler number $D_{\mathrm{m}}=\left(\delta_{\mathrm{m}} / \delta_{\mathrm{L}}\right)^{2} \gg 1$, while $U_{0} / S_{\mathrm{L}}$ and $U_{\mathrm{A}} / U_{0}$ appear as additional parameters.

We must stress here that the above formulation for the lifted flame regime is dependent on the separation in domains of the flow field, which is justified for large values of the ratio, $x_{\mathrm{f}}^{\prime} / \delta_{\mathrm{m}}=\left(x_{\mathrm{f}}^{\prime} U_{0} / D_{\mathrm{TA}}\right)^{1 / 2}$, of the scales $x_{\mathrm{f}}^{\prime}$, of the nonreacting region of the mixing layer, and $\delta_{\mathrm{m}}$, of the flame-front region. The ratio $\delta_{\mathrm{m}} / \delta_{\mathrm{L}}=D_{\mathrm{m}}^{1 / 2}$ appearing in Eqs. (25)-(27), of the order of the Reynolds number $R e=S_{\mathrm{L}} \delta_{\mathrm{m}} / \nu_{\mathrm{A}}$, is a large number. As a result, the viscous and diffusion terms, as well as the reaction term, are nonnegligible only in a thin reaction layer, the curved premixed flame with its rich and lean branches, of thickness $\delta_{\mathrm{L}}$, small compared with $\delta_{\mathrm{m}}$. The flow in the flame front region outside this thin flame is inviscid; and for this reason the upstream boundary conditions given in Eq. (28) are meaningful. Then, aside from jumps across the premixed flames, the temperature and the mass fractions remain constant along the streamlines, which are nonparallel due to the thermal expansion effects. In the limit $D_{\mathrm{m}} \gg 1$, one could in principle solve the flow in the flame-front region by considering the flame as a curved reaction sheet embedded in the inviscid flow region, but as previously discussed the numerical solution of the resulting free boundary problem is anticipated to be difficult. The alternative approach proposed here, and used by Ruetsch et al. [30], involves the integration of Eqs. (24) (27) for large values of $D_{\mathrm{m}}$. As shown below, the results, and in particular the value for the front velocity $U_{\mathrm{f}} / S_{\mathrm{L}}$, are weakly dependent on $D_{\mathrm{m}}$ when sufficiently large values are considered. Correspondingly, at a given transverse location the flame propagates with respect to the local incoming flow with a velocity equal to that of a planar flame, which is a function of the local equivalence ratio $\phi=s Y_{\mathrm{CH}_{4}, u} / Y_{\mathrm{O}_{2}, u}$ encountered by the flame, with $Y_{\mathrm{CH}_{4}, u}$ and $Y_{\mathrm{O}_{2}, u}$ defined in terms of $Y_{\mathrm{CH}_{4}}$ and $Y_{\mathrm{O}_{2}}$ by Eqs. (15) and (16). As previously discussed, this variation of the planar-flame velocity with $\phi$ enters as the essential ingredient of the influence of the kinetics on the flame-front structure.

As suggested by Eqs. (25)-(27), the ratio $\delta_{\mathrm{m}} / \delta_{\mathrm{L}}=$ $D_{\mathrm{m}}^{1 / 2}$ represents an alternative Damköhler number based on the residence time across the flame-front region, $\delta_{\mathrm{m}} / U_{0}$, and the chemical time, $\delta_{\mathrm{L}} / U_{0}$. However, we have chosen here to formulate the problem using the classical Damköhler number $D_{\mathrm{m}}=$ $\left(\delta_{\mathrm{m}} / \delta_{\mathrm{L}}\right)^{2} \sim 1 /\left(\chi_{\mathrm{s}} t_{\mathrm{L}}\right)$, defined in terms of the local value of the scalar dissipation rate at the stoichiometric surface, $\chi_{\mathrm{s}}=D_{\mathrm{TA}}|\nabla Z|_{\mathrm{s}}^{2}$-inverse of the characteristic diffusion time, $\delta_{\mathrm{m}}^{2} / D_{\mathrm{TA}}$ - and the characteristic chemical time, $t_{\mathrm{L}}=\delta_{\mathrm{L}}^{2} / D_{\mathrm{TA}}$. Remember that in this context the Damköhler number $D_{\mathrm{m}}$ can be viewed as the square of the Reynolds number of the flow in the flame-front region.

\section{Results and discussion}

In this section we discuss the numerical results obtained from the integration of the equations in the attached and lifted flame regimes. As previously stated, the results reported in this paper correspond to the case where the velocities of the fuel and oxidizer stream are equal, $U_{\mathrm{A}} / U_{0}=1$, for which a uniform velocity profile $u^{\prime}=U_{0}$ is found on the injection wall (attached flame regime) or upstream from the flamefront region (lifted flame regime). Remember that the effects of thermal expansion in the upstream boundary can be minimized when calculating lifted flames by extending the computational domain sufficiently far upstream from the flame-front region.

In the attached flame regime, one specifies the Damköhler number $D_{\mathrm{N}}=\left(S_{\mathrm{L}} / U_{0}\right)^{2}$ and obtains the dimensionless position $x_{\mathrm{f}}^{\prime} / l_{\mathrm{N}}$ of the steady flame front by integrating the problem (1)-(11) together with Eqs. (13)-(17). Then, the position of the flame front $x_{\mathrm{f}}^{\prime}$ is defined as the distance to the wall of the point of intersection of the stoichiometric isosurface $Z=Z_{S}=1 /(1+S)$ and the temperature isosurface $T=1200 \mathrm{~K}$, which is close to the point of maximum heat release for all the fuel dilutions considered.

In the lifted flame regime, on the other hand, one specifies the Damköhler number

$$
D_{\mathrm{m}}=\left(\delta_{\mathrm{m}} / \delta_{\mathrm{L}}\right)^{2}=D_{\mathrm{TA}} x_{\mathrm{f}}^{\prime} / U_{0} \delta_{\mathrm{L}}^{2}=\left(x_{\mathrm{f}}^{\prime} / l_{\mathrm{N}}\right) D_{\mathrm{N}}
$$


and integrates the problem (25)-(31) together with Eqs. (13)-(17), which yields the propagation velocity of the flame front with respect to the injector, $U_{\mathrm{f}} / S_{\mathrm{L}}$, as an eigenvalue.

As discussed in the Introduction, the results will be given mainly for methane, although they are expected to be similar for other fuels (as will be shown for propane in Section 4.5).

\subsection{Numerical method}

The conservation equations are discretized using second-order centered finite differences, and the resulting set of algebraic equations are solved using false time-step relaxation for each of the dependent variables. The convergence of the iterative procedure is truncated once the normalized residuals are below $10^{-5}$.

The computational domain is discretized using a Cartesian-structured grid. In the attached flame calculations, the grid extends from the injection wall to $x / l_{\mathrm{N}}=300$ in the streamwise direction, and from $y / l_{\mathrm{N}}=-300$ to $y / l_{\mathrm{N}}=200$ in the transverse direction. The grid spacing is uniform in the region $0 \leqslant$ $x / l_{\mathrm{N}} \leqslant 180,-60 \leqslant y / l_{\mathrm{N}} \leqslant 0$, where the front lies in all the cases under consideration, and is smoothly stretched outside this region. In the lifted flame calculations, the size of the computational domain was selected to account for the slowly decaying perturbations induced by the thermal expansion at the flame front, covering in the most restrictive case (i.e., for the higher values of the Damköhler number $D_{\mathrm{m}}$ ) the region $-3.46 \leqslant x / \delta_{\mathrm{m}} \leqslant 3.46,-17.30 \leqslant y / \delta_{\mathrm{m}} \leqslant 34.6$. The errors associated with the finite size of the domain are estimated to be less than $2 \%$. Uniform grid spacing is used in either direction in the hightemperature zone, where the gradients of all variables are higher. In the most restrictive case this uniformly spaced region covers $-0.1 \leqslant x / \delta_{\mathrm{m}} \leqslant 0.1,-1.1 \leqslant$ $y / \delta_{\mathrm{m}} \leqslant 1.1$, and as we move away from this region the grid node density decreases smoothly. In the lifted flame regime, the eigenvalue $U_{\mathrm{f}} / S_{\mathrm{L}}$ is obtained with the same algorithm used in [52]. In all cases, the total number of grid points is close to 42,000 , from which about 26,000 were located in the high temperature zone. Moreover, the structure of the curved premixed flame was solved using at least 10 points in either direction.

Extensive grid refinement studies were conducted to assess the accuracy of the results presented here. In particular, the numerical (roundoff and truncation) error present in the eigenvalue $U_{\mathrm{f}} / S_{\mathrm{L}}$ was found to be much smaller than the error associated with the finite size of the computational domain noted above.

\subsection{Flame-front structure}

Figs. 3 and 4 show the flame-front structure obtained for undiluted fuel feed, $Y_{\mathrm{CH}_{4}, \mathrm{~F}}=1$, and different values of the Damköhler number for $U_{\mathrm{A}} / U_{0}=1$. The results of Fig. 3 correspond to the attached flame regime, while those of Fig. 4 correspond to the lifted flame regime. The selected range of Damköhler numbers illustrates the evolution of the flame front from an edge flame for sufficiently small (large) values of $D_{\mathrm{m}}\left(D_{\mathrm{N}}\right)$ to a thin premixed front with a negligibly weak trailing diffusion flame for $D_{\mathrm{m}} \rightarrow \infty$ $\left(D_{\mathrm{N}} \rightarrow 0\right)$. Fig. $3 \mathrm{c}^{\prime}$ was generated replotting Fig. $3 \mathrm{c}$ using for illustrative purposes the characteristic length scale $\delta_{\mathrm{m}}=l_{\mathrm{N}}\left(x_{\mathrm{f}}^{\prime} / l_{\mathrm{N}}\right)^{1 / 2}$ of the lifted flame regime. Comparing Fig. $3 \mathrm{c}^{\prime}$ with Fig. $4 \mathrm{~d}$ reveals that both analysis, i.e., the attached and the lifted flame formulations, yield the same results in the overlap domain for intermediate values of the Damköhler number. All the plots in Figs. 3 and 4 have been labeled with the values of both Damköhler numbers, $D_{\mathrm{m}}$ and $D_{\mathrm{N}}$, which are related by Eq. (32). Finally, it should be noted that in Fig. 4 the origin of the transversal coordinate has been displaced so as to locate the stoichiometric surface close to $y^{\prime}=0$ in the upstream boundary of the computational domain.

For $\beta \gg 1$, the transition from edge flames to triple flames should occur when the more relevant Damköhler number $\left[\delta_{\mathrm{m}} /\left(\beta \delta_{\mathrm{L}}\right)\right]^{2}$, based on the effective size $\delta_{\mathrm{m}} / \beta$ of the flame-front region, increases above 1 . Note that $\delta_{\mathrm{m}} /\left(\beta \delta_{\mathrm{L}}\right)$ is also the ratio of the burning rate per unit flame surface in the premixed and in the diffusion flames, so that for large values of the Damköhler number the contribution of the burning rate in the diffusion flame ceases to be visible. For pure methane-air flames, $Y_{\mathrm{CH}_{4}, \mathrm{~F}}=1$, the dimensionless stoichiometric temperature increase is $\gamma=\left(T_{\mathrm{s}}-T_{0}\right) / T_{0}=6.7$, and the resulting Zeldovich number based on $E_{0}, \beta=$ $E_{0}\left(T_{\mathrm{s}}-T_{0}\right) /\left(R T_{\mathrm{s}}^{2}\right)=5.7$, is moderately large. Then, the transition from edge flames to triple flames is expected to occur around $D_{\mathrm{m}}=\left(\delta_{\mathrm{m}} / \delta_{\mathrm{L}}\right)^{2} \sim \beta^{2} \simeq 32.5$, corresponding approximately to the case shown in Fig. 3c.

It should be noted that the direction of the trailing diffusion flame does not necessarily coincide with the incoming flow direction when, for small values of $D_{\mathrm{m}}$, the flame is anchored close to the injection wall. However, as the Damköhler number grows the flame becomes more and more aligned with the flow, until for sufficiently large values of $D_{\mathrm{m}}$ the trailing diffusion flame becomes almost parallel to the $x$ axis.

As demonstrated by recent studies, chemistry may play a key role in the description of the flamefront structure of attached flames in axisymmetric 
(a) $D_{\mathrm{m}}=14.7, D_{\mathrm{N}}=3$

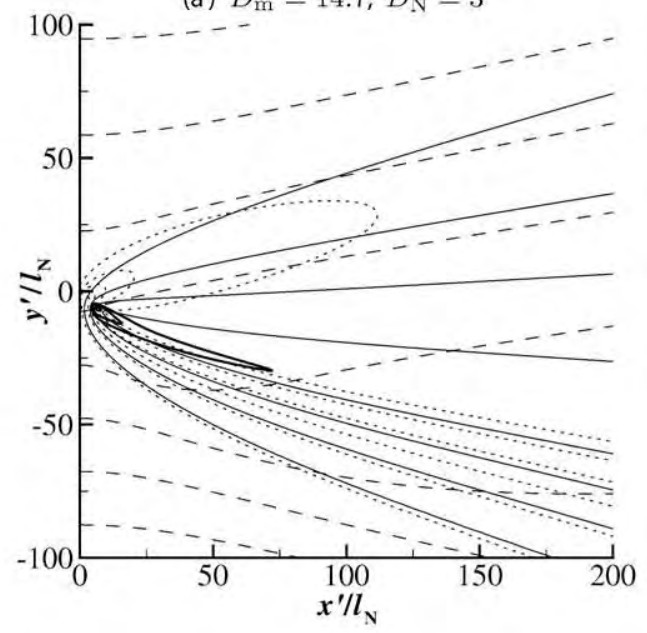

(c) $D_{\mathrm{m}}=38.1, D_{\mathrm{N}}=0.3$

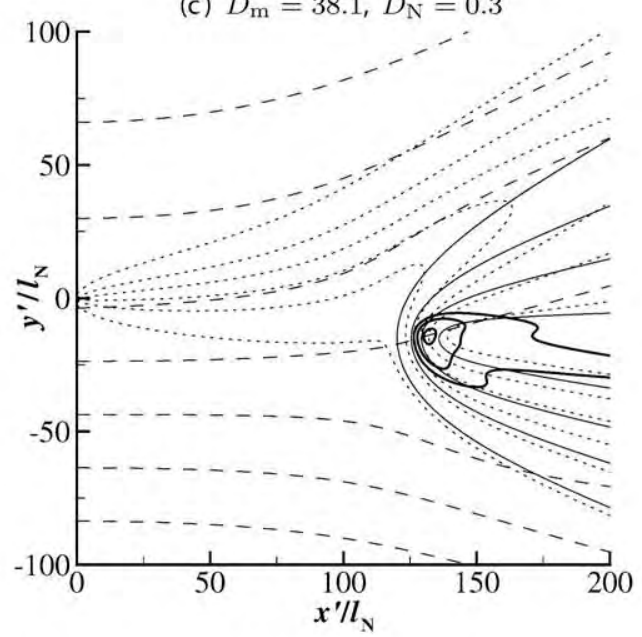

(b) $D_{\mathrm{m}}=26.9, D_{\mathrm{N}}=0.6$

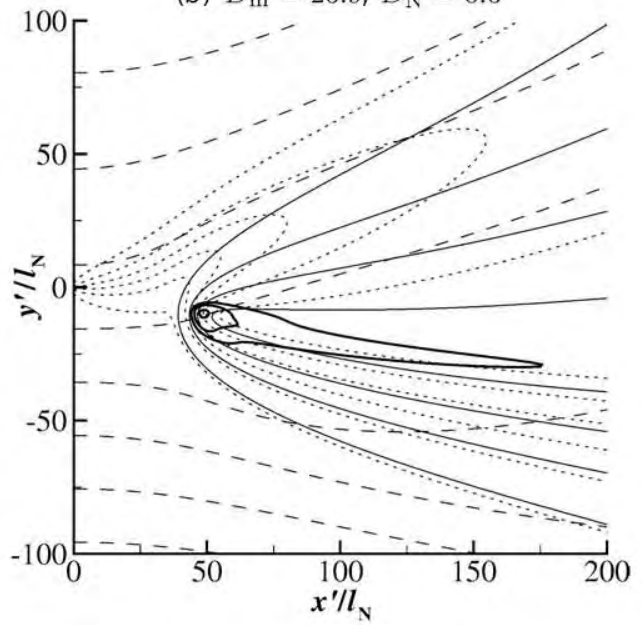

(c') $D_{\mathrm{m}}=38.1, D_{\mathrm{N}}=0.3$

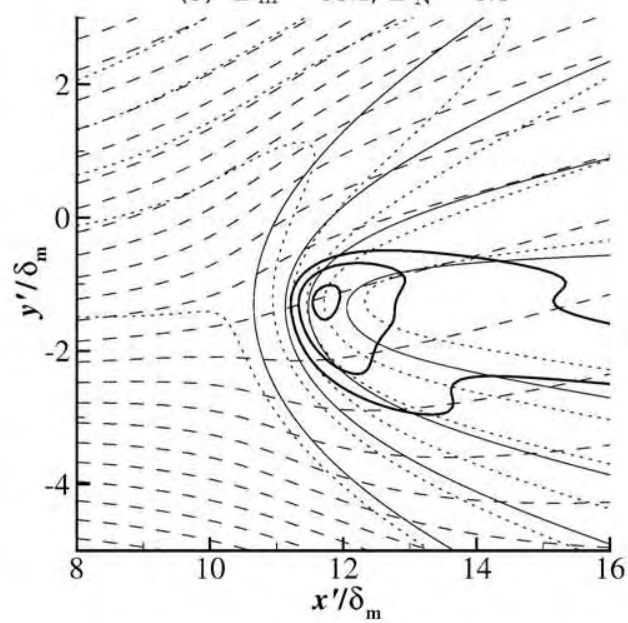

Fig. 3. Flame-front structure in the attached flame regime for undiluted fuel $\left(Y_{\mathrm{CH}_{4}, \mathrm{~F}}=1\right)$ and different values of the Damköhler number. The plots correspond to points labeled $3 \mathrm{a}-3 \mathrm{c}$ in Figs. 5 and 6 . Thick solid lines: reaction rate contours for $\beta^{2} \omega_{\mathrm{CH}_{4}}=\left(\beta^{2} / D_{\mathrm{m}}\right)\left(\omega_{\mathrm{CH}_{4}}^{\prime} l_{\mathrm{N}}\right) /\left(U_{0} \rho_{\mathrm{A}}\right)=0.1,0.3$, and 1 with $\beta=5.7$. Thin solid lines: temperature contours from 500 to $2000 \mathrm{~K}$ at intervals $\Delta T=500 \mathrm{~K}$. Dashed lines: streamlines at intervals (a)-(c) $\Delta \psi=20 \rho_{\mathrm{A}} U_{0} l_{\mathrm{N}}$ and $\left(\mathrm{c}^{\prime}\right) \Delta \psi=0.25 \rho_{\mathrm{A}} U_{0} \delta_{\mathrm{m}}$. Dotted lines: oxygen mass fraction $Y_{\mathrm{O}_{2}}$ from 0.22 to 0.02 at intervals $\Delta Y_{\mathrm{O}_{2}}=0.04$.

methane-air jets. For example, the flame-front structure predicted using a classical one-step global chemistry model (with constant activation energy) shows a robust rich premixed wing [53] that is absent both in the detailed chemistry calculations $[53,54]$ and in experimental visualizations [21,55]. The missing rich wing seems to be folded into the diffusion flame due to a combination of configuration-dependent flow perturbations [56] and subtle chemistry effects [53,54]. Our calculations show that both wings coexist in the attached flames. This may be due to the different flow configuration or to the simplified kinetics considered, a point that should be clarified in future work.

\subsection{The liftoff distance}

The steady flame-front position, or liftoff distance, $x_{l}^{\prime}$, measured for convenience with the laminar flame thickness, $\delta_{\mathrm{L}}$, is plotted in Fig. 5 as a function of the velocity ratio $U_{0} / S_{\mathrm{L}}=D_{\mathrm{N}}^{-1 / 2}$. Note that, unlike $l_{\mathrm{N}}$, the laminar flame thickness is independent of the injection velocity and takes a constant value for each fuel. To emphasize the effects of thermal expansion the results obtained using the thermodiffusive approximation, where modification of the flow field by heat release is ignored, are also shown. The plot is completed with the results of the lifted flame regime, which have been presented 
(a) $D_{\mathrm{m}}=44.6, D_{\mathrm{N}}=0.26$

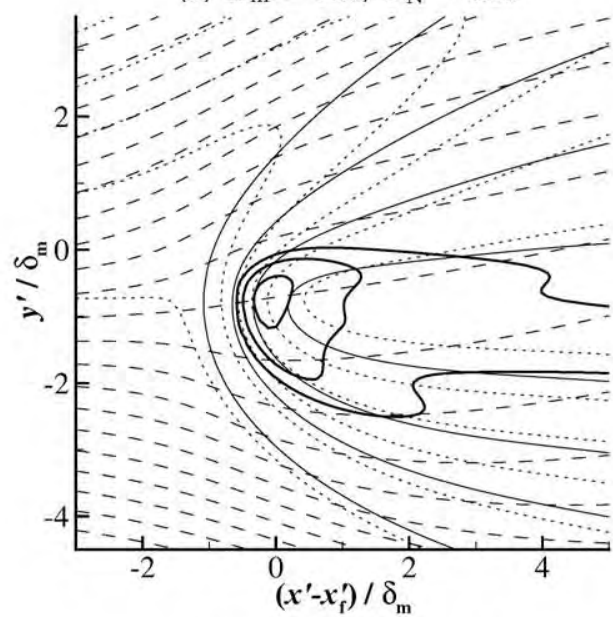

(c) $D_{\mathrm{m}}=531, D_{\mathrm{N}}=0.110$

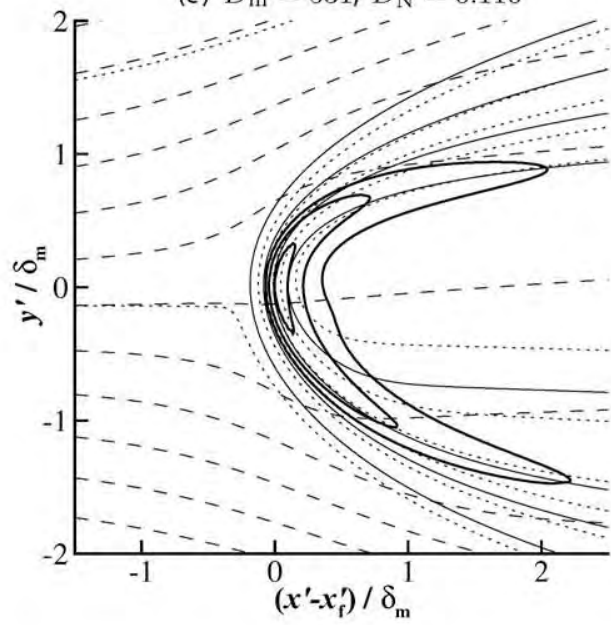

(b) $D_{\mathrm{m}}=137, D_{\mathrm{N}}=0.153$

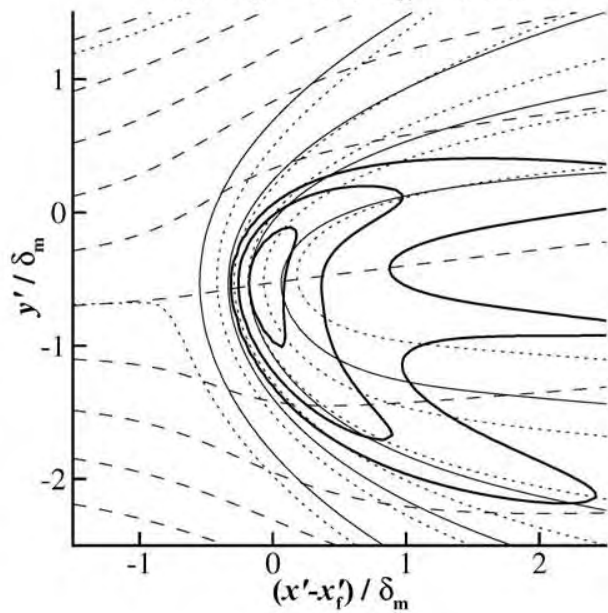

(d) $D_{\mathrm{m}}=4604, D_{\mathrm{N}}=0.091$

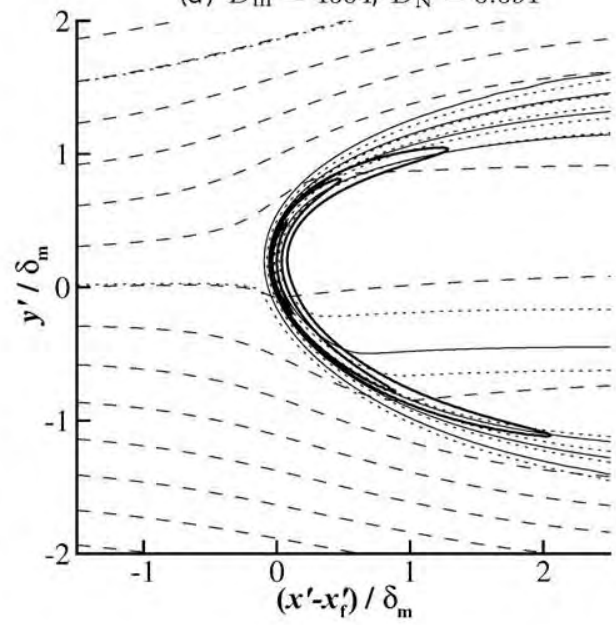

Fig. 4. Flame-front structure in the lifted flame regime for undiluted fuel $\left(Y_{\mathrm{CH}_{4}, \mathrm{~F}}=1\right)$ and different values of the Damköhler number. The plots correspond to points labeled $4 \mathrm{a}-4 \mathrm{~d}$ in Figs. 5 and 6 . Thick solid lines: reaction rate contours for $\beta^{2} \omega_{\mathrm{CH}_{4}}=\left(\beta^{2} / D_{\mathrm{m}}\right)\left(\omega_{\mathrm{CH}_{4}}^{\prime} l_{\mathrm{N}}\right) /\left(U_{0} \rho_{\mathrm{A}}\right)=0.1,0.3$, and 1 with $\beta=5.7$. Thin solid lines: temperature contours from 500 to $2000 \mathrm{~K}$ at intervals $\Delta T=500 \mathrm{~K}$. Dashed lines: streamlines at intervals $\Delta \psi=0.25 \rho_{\mathrm{A}} U_{0} \delta_{\mathrm{m}}$. Dotted lines: oxygen mass fraction $Y_{\mathrm{O}_{2}}$ from 0.22 to 0.02 at intervals $\Delta Y_{\mathrm{O}_{2}}=0.04$. Note the different scale of the axis of the first plot.

in terms of $D_{\mathrm{N}}=D_{\mathrm{m}} /\left(x_{\mathrm{f}}^{\prime} / l_{\mathrm{N}}\right)$ for illustrative purposes.

\subsection{Propagation velocity of the flame front relative to the upstream flow}

When the velocities of the fuel and air streams are equal, $U_{\mathrm{A}} / U_{0}=1$, as we are considering here, the computations provide the front velocity relative to the upstream flow $U_{\mathrm{f}}^{\prime}=-U_{\mathrm{f}}+U_{0}$ as an eigenvalue. Thus, for a given transport model, the resulting nondimensional propagation velocity $U_{\mathrm{f}}^{\prime} / S_{\mathrm{L}}$ is a function of the exothermicity parameter $\gamma$, the fuelto-air stoichiometric ratio $S$, the Damköhler number $D_{\mathrm{m}}=\left(\delta_{\mathrm{m}} / \delta_{\mathrm{L}}\right)^{2}$, the Zeldovich number $\beta=E_{0}\left(T_{\mathrm{S}}-\right.$
$\left.T_{0}\right) /\left(R T_{\mathrm{S}}^{2}\right)$, and the function $E(\phi) / E_{0}$, characterizing the chemical kinetics.

The propagation velocity $U_{\mathrm{f}}^{\prime} / S_{\mathrm{L}}$ of the front with respect to the upstream flow is shown in Fig. 6 as a function of the local Damköhler number $D_{\mathrm{m}}=$ $\left(\delta_{\mathrm{m}} / \delta_{\mathrm{L}}\right)^{2}$ for different dilutions of the fuel stream $Y_{\mathrm{CH}_{4}, \mathrm{~F}}$. As previously discussed, for sufficiently large values of $D_{\mathrm{m}}$ the velocity becomes weakly dependent on $D_{\mathrm{m}}$. In particular, the values of $U_{\mathrm{f}}^{\prime} / S_{\mathrm{L}}$ obtained for large (but finite) values of $D_{\mathrm{m}}$ can be extrapolated to $D_{\mathrm{m}} \rightarrow \infty$, assuming the asymptotic behavior

$$
U_{\mathrm{f}}^{\prime} / S_{\mathrm{L}}=\left(U_{\mathrm{f}}^{\prime} / S_{\mathrm{L}}\right)_{\mathrm{b}}\left(1-\Lambda D_{\mathrm{m}}^{-1 / 2}\right)
$$$$
\text { for } D_{\mathrm{m}} \gg 1
$$ 


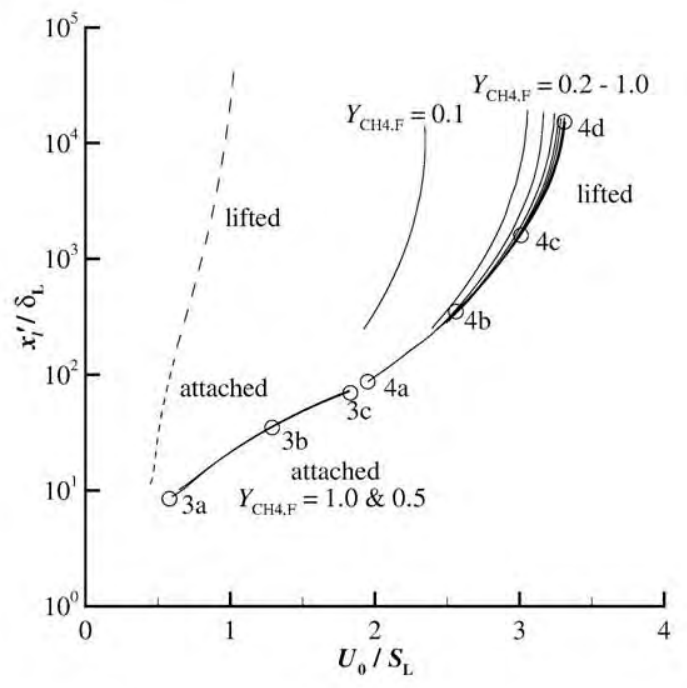

Fig. 5. Variation of the dimensionless liftoff distance $x_{l}^{\prime} / \delta_{\mathrm{L}}$ with the injection velocity ratio $U_{0} / S_{\mathrm{L}}=D_{\mathrm{N}}^{-1 / 2}$ for different dilutions of methane in the fuel stream $(-)$. The results obtained with the thermodiffusive approximation are also shown for comparison (---, -- -).

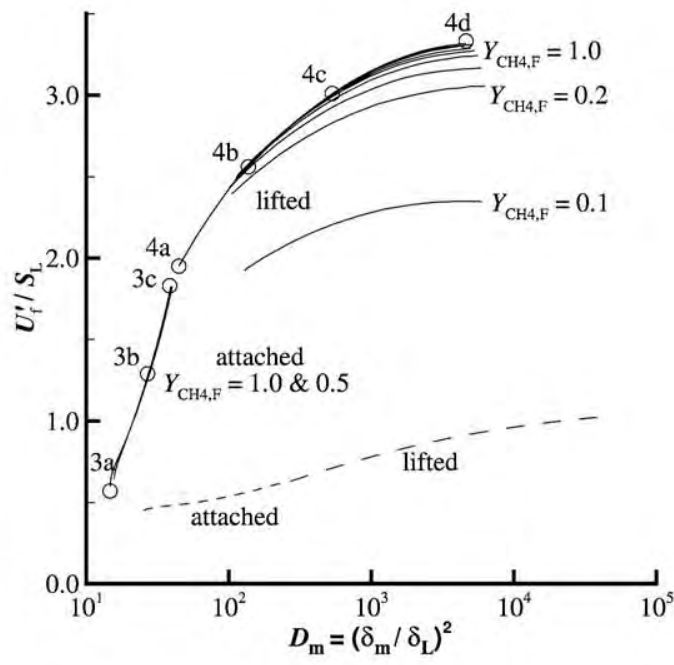

Fig. 6. Variation of the nondimensional flame-front velocity relative to the upstream flow $U_{\mathrm{f}}^{\prime} / S_{\mathrm{L}}$ with the Damköhler number $D_{\mathrm{m}}=\left(\delta_{\mathrm{m}} / \delta_{\mathrm{L}}\right)^{2}=D_{\mathrm{TA}} x_{\mathrm{f}}^{\prime} / U_{0} \delta_{\mathrm{L}}^{2}$ for different dilutions of methane in the fuel stream (-). The results obtained with the thermodiffusive approximation are also shown for comparison (-- - - - -).

determined by Daou and Liñán [28] in the context of triple flame propagation in counterflow (strained) mixing layers. This procedure provides a way to separate thermal expansion effects, given by the value of $\left(U_{\mathrm{f}}^{\prime} / S_{\mathrm{L}}\right)_{\mathrm{b}}$, from finite rate effects, given by the constant $\Lambda$. In particular, Fig. 7 shows the value of $\left(U_{\mathrm{f}}^{\prime} / S_{\mathrm{L}}\right)_{\mathrm{b}}$, obtained by a least-squares fit, as a func-

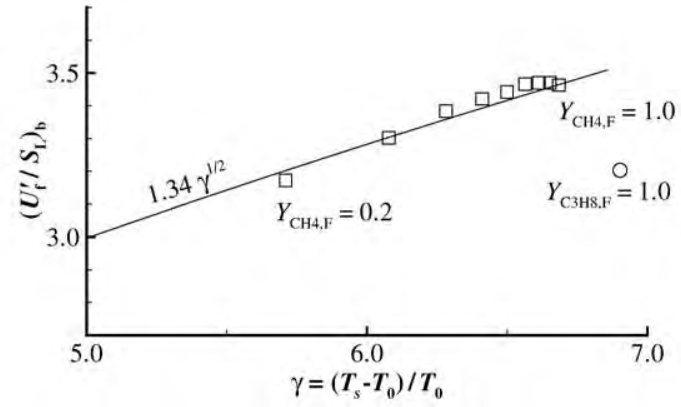

Fig. 7. Value of $\left(U_{\mathrm{f}}^{\prime} / S_{\mathrm{L}}\right)_{\mathrm{b}}$ extrapolated for $D_{\mathrm{m}} \rightarrow \infty$ from the numerical results as a function of the heat release parameter $\gamma=\left(T_{\mathrm{S}}-T_{0}\right) / T_{0}$ for diluted and undiluted methane $(\square)$ and for undiluted propane $(O)$, together with the least-squares fit $1.34 \gamma^{1 / 2}(-)$ valid for methane.

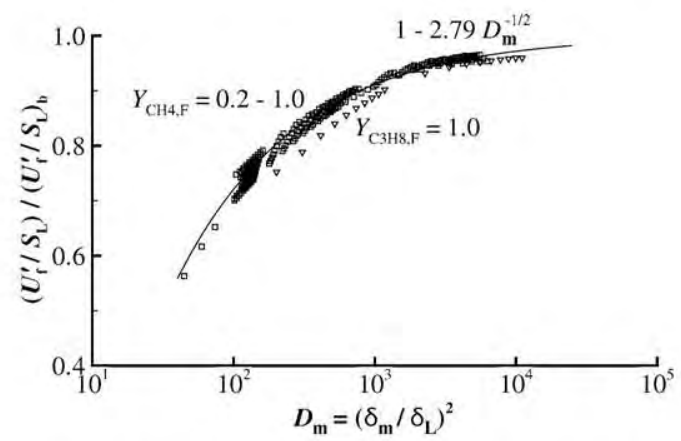

Fig. 8. Values of $\left(U_{\mathrm{f}}^{\prime} / S_{\mathrm{L}}\right) /\left(U_{\mathrm{f}}^{\prime} / S_{\mathrm{L}}\right)_{\mathrm{b}}$ as a function of $D_{\mathrm{m}}$ for different dilutions of methane in the fuel stream $(\square)$ and for undiluted propane $(\nabla)$, together with the least-squares fit $1-2.79 D_{\mathrm{m}}^{-1 / 2}(-)$. Here $\left(U_{\mathrm{f}}^{\prime} / S_{\mathrm{L}}\right)_{\mathrm{b}}=1.34 \gamma^{1 / 2}$ for diluted and undiluted methane, and $\left(U_{\mathrm{f}}^{\prime} / S_{\mathrm{L}}\right)_{\mathrm{b}}=3.20$ for undiluted propane.

tion of the heat release parameter, $\gamma=\left(T_{\mathrm{S}}-T_{0}\right) / T_{0}$, where $T_{\mathrm{S}}$ is the stoichiometric flame temperature corresponding to the fuel dilution considered in each case. Also shown is the curve fit

$\left(U_{\mathrm{f}}^{\prime} / S_{\mathrm{L}}\right)_{\mathrm{b}}=1.34 \gamma^{1 / 2}$,

where the dependence on $\gamma^{1 / 2}$ comes from the scaling law suggested by Ruetsch et al. [30] for large values of $D_{\mathrm{m}}$. The values of $\left(U_{\mathrm{f}}^{\prime} / S_{\mathrm{L}}\right)_{\mathrm{b}}$ predicted by (34) are seen to fit the computed results to within a $1.2 \%$ from $Y_{\mathrm{CH}_{4}}=0.2$ to 1.0 , which corresponds to values of $\gamma$ ranging from 5.7 to 6.7 , respectively. The value of the constant $\Lambda$ in (33) can also be determined by a least-squares fit. Fig. 8 illustrates that when the value $\Lambda=2.79$ is substituted into Eq. (33), and use is made of Eq. (34), the numerical results obtained for a wide interval of fuel dilutions, ranging from pure methane to $Y_{\mathrm{CH}_{4}, \mathrm{~F}}=0.2$, nearly collapse in a single curve for $D_{\mathrm{m}} \gtrsim 10^{2}$. However, this correlation ceases to be valid for stronger dilutions of the fuel stream. 
As observed in Fig. 6, for undiluted fuel feed the asymptotic value $\left(U_{\mathrm{f}}^{\prime} / S_{\mathrm{L}}\right)_{\mathrm{b}}=3.46$ is approached as $D_{\mathrm{m}} \rightarrow \infty$. This limiting value is associated with critical conditions for blowoff in planar mixing layers. For large but finite values of $D_{\mathrm{m}}$ the front propagation velocity is smaller than this asymptotic value, of the order of $3 S_{\mathrm{L}}$, a result in agreement with previous experimental observations (Muñiz and Mungal [57]). When the methane stream is diluted with nitrogen the results depend on the air-to-fuel mass stoichiometric ratio: $S=17.4$ for pure methane, and $S=3.48$ for $Y_{\mathrm{CH}_{4}, \mathrm{~F}}=0.2$. However, the effects of the dilution, for values of $Y_{\mathrm{CH}_{4}, \mathrm{~F}}$ larger than 0.2 , on the curve $U_{\mathrm{f}}^{\prime} / S_{\mathrm{L}}$ versus $D_{\mathrm{m}}$ are weak, with the peak blowoff velocity decreasing from $3.46 S_{\mathrm{L}}$ to $3.17 S_{\mathrm{L}}$ when $Y_{\mathrm{CH}_{4}, \mathrm{~F}}$ decreases from 1 to 0.2 . It should be noted, however, that the dilution strongly affects the value of $S_{\mathrm{L}}$ (see Fig. 2).

We can use Fig. 6 to calculate the liftoff distance $x_{l}^{\prime}$ for a given flow velocity $U_{0}$ by equating $U_{\mathrm{f}}^{\prime} / S_{\mathrm{L}}$ to $U_{0} / S_{\mathrm{L}}$. Note that due to the growth of $U_{\mathrm{f}}^{\prime} / S_{\mathrm{L}}$ with $x_{\mathrm{f}}^{\prime}$ the resulting position of the flame front is stable. For $U_{0} / S_{\mathrm{L}}$ smaller than the blowoff value $\left(U_{0} / S_{\mathrm{L}}\right)_{\mathbf{b}}=$ 3.46 the flame will remain lifted. It should be pointed out that the assumption of an overall Arrhenius reaction involving only four chemical species overpredicts the chemical equilibrium temperature by more than $100 \mathrm{~K}$. According to this, the blowoff velocities predicted here are expected to be slightly larger than those encountered in the experiments.

As a final remark, it should be pointed out that the asymptotic value of $U_{\mathrm{f}}^{\prime} / S_{\mathrm{L}}$ in jet-diffusion flames will be larger than its asymptotic value $\left(U_{\mathrm{f}}^{\prime} / S_{\mathrm{L}}\right)_{\mathrm{b}}$ for the planar mixing layer, due to the interacting thermal expansion effects of the different elements of the annular flame front when, for large liftoff heights - of the order of the jet developing length, $x_{\mathrm{f}}^{\prime} \sim L_{\mathrm{d}}$-the thickness of the mixing layer is comparable to the jet radius. In this case, the asymptotic value of $U_{\mathrm{f}}^{\prime} / S_{\mathrm{L}}$ should be determined using the general formulation for lifted jet-diffusion flames recently proposed by the authors [35].

\subsection{Application to other fuels}

To assess the applicability of the results to fuels different from methane, we calculated the front propagation velocity (relative to the upstream flow) in a pure propane-air mixing layer. Fig. $2 \mathrm{~b}$ shows that when the curves $U_{\mathrm{L}}(\phi)$ for methane and propane are normalized with $S_{\mathrm{L}}$, they turn out to be almost indistinguishable in the lean side; however, propane shows slightly larger velocities in the rich side and its equivalence ratio in the rich extinction limit is higher. Thus, to mimic the dependence of $U_{\mathrm{L}}$ on $\phi$ for propaneair mixtures it was necessary to modify the relation
$E(\phi)$ by substituting the constant 1.472 by 0.8 in the rich branch of Eq. (17), while $E_{0}$ was kept constant by choosing an appropriate value of the preexponential factor $B$ so as to reproduce the experimental value of $S_{\mathrm{L}}$. The Lewis number of propane was set equal to 1.26 , a first approximation suggested in [58], founded on the assumption that the binary diffusion coefficient of species $\alpha$ with respect to nitrogen is, according to the kinetic theory of gases [59], approximately proportional to $\left[\left(M_{\alpha}+M_{\mathrm{N}_{2}}\right) /\left(2 M_{\alpha} M_{\mathrm{N}_{2}}\right)\right]^{1 / 2}$.

Results for undiluted propane are shown in Figs. 7 and 8 . As can be seen, when measured with $S_{\mathrm{L}}$ the blowoff velocity for propane is slightly smaller than for methane, even though the curve $U_{\mathrm{L}} / S_{\mathrm{L}}$ versus $\phi$ shows slightly larger propagation velocities in the rich side as well as a richer extinction limit. Certainly, the higher propagation velocities of the rich branch of the triple flame is partly balanced by the effect of the fuel Lewis number being greater than unity, which is known to reduce the propagation velocity of triple flames [28]. However, the main reason seems to be the higher inertia, i.e., density, of the upstream fresh mixture in the rich side of the mixing layer, which curves the rich branch of the triple flame backward (compared to the methane flame) and thus reduces the deflection of the streamlines upstream of the front.

From the above discussion, we can anticipate that, as long as the appropriate characteristic scales are used, the results of our analysis will be applicable to other fuels not strongly diluted, having values of $\gamma$ close to that of methane or propane, and with large values of $S$.

\section{Conclusions}

In this paper we have presented the formulation required for the numerical description of the structure and quasi-steady propagation of laminar flame fronts in planar mixing layers between two parallel streams of fuel and air emerging from porous walls. First, we describe the steady flame-front structure when, for $x_{l}^{\prime} \sim l_{\mathrm{N}}$, the flame front is attached close to the injection wall. Then we describe the quasi-steady flamefront region of lifted diffusion flames, exploiting the disparity of scales appearing for moderately large values of the Damköhler number $D_{\mathrm{m}}=\left(\delta_{\mathrm{m}} / \delta_{\mathrm{L}}\right)^{2}$.

The formulation given incorporates realistic variations of density and transport coefficients with temperature and composition. In addition, a realistic model for the fuel consumption rate, able to describe the variation with the equivalence ratio of the propagation velocity of planar flames, was employed for an accurate computation of flame-front velocities. The limitations arising from the simplified chemistry model considered here could be eliminated using a re- 
duced or detailed chemical mechanism. However, in this paper our purpose was rather to provide a general understanding of the effects of the overall stoichiometric ratio $S$, the thermal expansion $\gamma$, and chemical kinetic rates on freely propagating (lifted) laminar flame fronts, so that a simple chemistry model was preferred.

The numerical results, obtained here for a uniform velocity profile, $U_{\mathrm{A}}=U_{0}$, of the attached and the lifted flame regimes provide the liftoff distance as well as the front propagation velocity (relative to the upstream flow) in terms of the relevant Damköhler numbers, $D_{\mathrm{N}}$ and $D_{\mathrm{m}}$, which are related by Eq. (32). As previously observed, the front propagation velocity is seen to grow well above the stoichiometric flame velocity $S_{\mathrm{L}}$, reaching values of the order of three times larger than $S_{\mathrm{L}}$ due to the well-known mechanism of flow redirection ahead of the curved flame front. As should be expected, the results of both analyses coincide in the domain of overlap for intermediate values of $D_{\mathrm{m}}$.

It should be noted that in the formulation of the problem we have chosen characteristic scales-such as the planar stoichiometric flame velocity or the laminar flame thickness - that represent the chemical kinetics, because we think this will make the results applicable to other fuels. As an example, we have presented results for undiluted propane that show only small differences with respect to methane when these characteristic scales are used.

The nondimensional blowoff velocities $\left(U_{\mathrm{f}}^{\prime} / S_{\mathrm{L}}\right)_{\mathrm{b}}$, obtained extrapolating the numerical results for $D_{\mathrm{m}}$ $\rightarrow \infty$, are in good agreement with previous experimental results [57]. For methane diluted with nitrogen, these velocities are seen to grow with the square root of the heat release parameter $\gamma=\left(T_{\mathrm{s}}-T_{0}\right) / T_{0}$, as predicted by Ruetsch et al. [30] for large $\gamma$, the constant of proportionality being approximately equal to 1.34 . In addition, preliminary results for undiluted propane suggest that the nondimensional blowoff velocity turns out to be slightly smaller for heavier fuels, decreasing from 3.46 for methane to 3.20 for propane Although this reduction may be due to Lewis number effects, which tend to reduce the propagation velocity of triple flames for Lewis numbers larger than one, it is more probably related to the higher inertia of the upstream fresh mixture in the rich side of the mixing layer, which curves the rich branch of the triple flame backward and thus reduces the deflection of the streamlines upstream of the front.

For nonuniform velocity profiles, $U_{\mathrm{A}}<U_{0}$, the effect of the velocity gradient that develops across the mixing layer is anticipated to be important when $S$ is large and the coflow velocity ratio $U_{\mathrm{A}} / U_{0}$ is small compared with unity. In this case, the blowoff value of $U_{0} / S_{\mathrm{L}}$ is anticipated to be of order $S$. This relevant regime is not addressed in this paper and deserves further attention.

It should be noted that radiation has been ignored in the present study. However, it certainly contributes to the flame heat loss and to the heat flux from the high-temperature front to the porous wall, and should be included in any comprehensive detailed study.

\section{Acknowledgments}

This work was supported by the Instituto Nacional de Técnica Aeroespacial (INTA), under Programme IGB 4400903. It has also been supported by the Spanish MCYT under Project No. BFM 2001-3691. Part of the work of the senior author was carried out at Yale University, in cooperation with Professor M.D. Smooke and co-workers, during his stays as Adjunct Professor.

\section{References}

[1] A. Liñán, in: C.F. Brauner, C. Schmidt-Lain (Eds.), Mathematical Modelling in Combustion and Related Topics, in: NATO ASI Series E, vol. 140, Nijhoff, The Netherlands, 1988, pp. 151-154.

[2] F. Takahashi, V.R. Katta, Proc. Combust. Inst. 23 (1990) 677-683.

[3] S.H. Chung, B.J. Lee, Combust. Flame 86 (1991) 6272.

[4] A. Liñán, in: J. Buckmaster, T.L. Jackson, A. Kumar (Eds.), Combustion in High-Speed Flows, Kluwer Academic, Dordrecht/Norwell, MA, 1994, pp. 461-476.

[5] B.J. Lee, S.H. Chung, Combust. Flame 109 (1997) $163-172$.

[6] F. Takahashi, W.J. Schmoll, V.R. Katta, Proc. Combust. Inst. 27 (1998) 675-684.

[7] E. Fernández, V. Kurdyumov, A. Liñán, Proc. Combust. Inst. 28 (2000) 2125-2131.

[8] V. Kurdyumov, E. Fernández-Tarrazo, A. Liñán, Aerospace Sci. Technol. 2 (1998) 507-516.

[9] A. Revuelta, A.L. Sánchez, A. Liñán, Combust. Flame 128 (2002) 199-210.

[10] J. Buckmaster, P. Clavin, A. Liñán, M. Matalon, N. Peters, G. Sivashinsky, F.A. Williams, Proc. Combust. Inst. 30 (2005) 1-19.

[11] J. Réveillon, P. Domingo, L. Vervisch, in: Tenth Symposium on Turbulent Shear Flows, University Park, PA, 1995, pp. 14-16.

[12] L. Vervisch, T. Poinsot, Annu. Rev. Fluid Mech. 30 (1998) 655-692.

[13] V. Favier, L. Vervisch, Proc. Combust. Inst. 27 (1998) 1239-1245.

[14] N. Peters, Turbulent Combustion, Cambridge Univ. Press, Cambridge, UK, 2000.

[15] C. Pantano, J. Fluid Mech. 514 (2004) 231-270.

[16] H. Phillips, Proc. Combust. Inst. 10 (1965) 1277-1283.

[17] P.N. Kioni, B. Rogg, K.N.C. Bray, A. Liñán, Combust. Flame 95 (1993) 276-290. 
[18] M.L. Shay, P.D. Ronney, Combust. Flame 112 (1998) 171-180.

[19] Y.S. Ko, S.H. Chung, Combust. Flame 118 (1999) 151163.

[20] R. Azzoni, S. Ratti, S.K. Aggarwal, I.K. Puri, Combust. Flame 119 (1999) 23-40.

[21] K.A. Watson, K.M. Lyons, J.M. Donbar, C.D. Carter, Combust. Flame 119 (1999) 199-202.

[22] V.S. Santoro, A. Liñán, A. Gomez, Proc. Combust. Inst. 28 (2000) 2039-2046.

[23] S.K. Aggarwal, I.K. Puri, X. Qin, Phys. Fluids 13 (2001) 265-275.

[24] W.F. Carnell Jr., M.W. Renfro, Combust. Flame 141 (2005) 350-359.

[25] J.W. Dold, Combust. Flame 76 (1989) 71-88.

[26] J.W. Dold, L.J. Hartley, D. Green, in: P.C. Fife, A. Liñán, F.A. Williams (Eds.), Dynamical Issues in Combustion Theory, in: IMA Volumes in Mathematics and Its Applications, vol. 35, Springer-Verlag, New York, 1991, pp. 83-105.

[27] L.J. Hartley, J.W. Dold, Combust. Sci. Technol. 80 (1991) 23-46.

[28] J. Daou, A. Liñán, Combust. Theory Modeling 2 (1998) 449-477.

[29] J. Buckmaster, Combust. Sci. Technol. 115 (1996) 4168.

[30] G.R. Ruetsch, L. Vervisch, A. Liñán, Phys. Fluids 7 (1995) 1447-1454

[31] X. Qin, C.W. Choi, A. Mukhopadhyay, I.K. Puri, S.K. Aggarwal, V.R. Katta, Combust. Theory Modeling 8 (2004) 293-314.

[32] N. Peters, Proc. Combust. Inst. 21 (1986) 1231-1250.

[33] J. Buckmaster, Prog. Energy Combust. Sci. 28 (2002) 435-475.

[34] K.T. Walsh, J. Fielding, M.D. Smooke, M.B. Long, A. Liñán, Proc. Combust. Inst. 30 (2005) 357-365.

[35] A. Liñán, E. Fernández-Tarrazo, M. Vera, A.L. Sánchez, Combust. Sci. Technol. 177 (2005) 933-953.

[36] V.N. Kurdyumov, M. Matalon, Proc. Combust. Inst. 29 (2002) 45-52.

[37] M.D. Smooke, V. Giovangigli, in: M.D. Smooke (Ed.), Reduced Kinetic Mechanisms and Asymptotic Approximations for Methane-Air Flames, Springer-Verlag, Berlin, 1990, pp. 1-28.

[38] G. Smith, D. Golden, M. Frenklach, N. Moriarty, B. Eiteneer, M. Goldenberg, T. Bowman, R. Hanson, S. Song, W. Gardiner Jr., V. Lissianski, Z. Qin, GRIMech, http://www.me.berkeley.edu/gri mech/, 1999.

[39] C.K. Westbrook, F.L. Dryer, Combust. Sci. Technol. 27 (1981) 31-43.
[40] D. Garrido-López, S. Sarkar, Proc. Combust. Inst. 30 (2005) 621-628.

[41] F.N. Egolfopoulos, D.L. Zhu, C.K. Law, Proc. Combust. Inst. 23 (1990) 471-478.

[42] C.K. Law, in: N. Peters, B. Rogg (Eds.), Reduced Kinetic Mechanisms for Application in Combustion Systems, Springer-Verlag, Berlin, 1993, pp. 15-26.

[43] F.N. Egolfopoulos, C.K. Law, Combust. Flame 80 (1990) 7-16.

[44] H.K. Chelliah, C.K. Law, T. Ueda, M.D. Smooke, F.A. Williams, Proc. Combust. Inst. 23 (1990) 503-511.

[45] J. Hsu, S. Mahalingam, Combust. Theory Modeling 7 (2003) 365-382.

[46] J. Du, R.L. Axelbaum, Proc. Combust. Inst. 26 (1996) 1137-1142.

[47] H.K. Chelliah, K. Seshadri, C.K. Law, in: N. Peters, B. Rogg (Eds.), Reduced Mechanisms for Applications in Combustion Systems, in: Lecture Notes in Physics, vol. 15, Springer-Verlag, Berlin, 1993, pp. 224-240.

[48] S.H. Chung, S.R. Lee, F. Mauss, N. Peters, in: N. Peters, B. Rogg (Eds.), Reduced Mechanisms for Applications in Combustion Systems, in: Lecture Notes in Physics, vol. 15, Springer-Verlag, Berlin, 1993, pp. 308-328.

[49] E.J.P. Zegers, B.A. Williams, E.M. Fisher, J.W. Fleming, R.S. Sheinson, Combust. Flame 121 (2000) 471487.

[50] B.A. Williams, Combust. Flame 124 (2001) 330-333.

[51] A. Liñán, A. Crespo, Combust. Sci. Technol. 14 (1976) 95-117.

[52] V.N. Kurdyumov, E. Fernández-Tarrazo, Combust. Flame 128 (2002) 382-394.

[53] F. Takahashi, V.R. Katta, Proc. Combust. Inst. 28 (2000) 2071-2078.

[54] F. Takahashi, V.R. Katta, Proc. Combust. Inst. 30 (2005) 375-382.

[55] L.K. Su, D. Han, M.G. Mungal, Proc. Combust. Inst. 28 (2000) 327-334.

[56] D. Veynante, L. Vervisch, T. Poinsot, A. Liñán, G. Ruetsch, in: Proceedings of the 1994 Summer Program, Center for Turbulence Research, Stanford University, Stanford, CA, 1994, pp. 55-73.

[57] L. Muñiz, M.G. Mungal, Combust. Flame 111 (1997) 16-31.

[58] N. Peters, Fifteen Lectures on Laminar and Turbulent Combustion, ERCOFTAC Summer School, Aachen, Germany, 1992.

[59] J.O. Hirschfelder, C.F. Curtis, R.B. Bird, Molecular Theory of Gases and Liquids, Wiley, New York, 1954. 